$12 / 530-95750$

ANL/ESD/TM-80

\title{
Utilization of Surface-Treated Rubber Particles from Waste Tires
}

Energy Systems Division Argonne National Laboratory

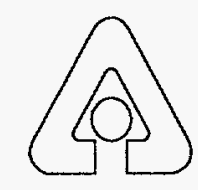

Operated by The University of Chicago, under Contract W-31-109-Eng-38, for the United States Department of Energy 


\section{Argonne National Laboratory}

Argonne National Laboratory, with facilities in the states of Illinois and Idaho, is owned by the United States Government, and operated by the University of Chicago under the provisions of a contract with the Department of Energy.

This technical memo is a product of Argonne's Energy Systems (ES)

Division. For information on the division's scientific and engineering activities, contact:

Director, Energy Systems Division

Argonne National Laboratory

Argonne, Illinois 60439-4815

Telephone (708) 252-3724

Presented in this technical memo are preliminary results of ongoing work or work that is more limited in scope and depth than that described in formal reports issued by the ES Division.

Publishing support services were provided by Argonne's Information and Publishing Division.

\section{Disclaimer}

This report was prepared as an account of work sponsored by an agency of the United States Government. Neither the United States Government nor any agency thereof, nor any of their employees, makes any warranty, express or implied, or assumes any legal liability or responsibility for the accuracy, completeness, or usefulness of any information, apparatus, product, or process disclosed, or represents that its use would not infringe privately owned rights. Reference herein to any specific commercial product, process, or service by trade name, trademark, manufacturer, or otherwise, does not necessarily constitute or imply its endorsement, recommendation, or favoring by the United States Government or any agency thereof. The views and opinions of authors expressed herein do not necessarily state or reflect those of the United States Government or any agency thereof.

Reproduced directly from the best available copy.

Available to $D O E$ and DOE contractors from the Office of Scientific and Technical Information, P.O. Box 62, Oak Ridge, TN 37831; prices available from (615) 576-8401.

Available to the public from the National Technical Information Service, U.S. Department of Commerce, 5285 Port Royal Road, Springfield, VA 22161. 


\section{DISCLAIMER}

Portions of this document may be illegible in electronic image products. Images are produced from the best available original document. 


\section{Utilization of Surface-Treated Rubber Particles from Waste Tires}

by F.G. Smith*

Energy Systems Division,

Argonne National Laboratory, 9700 South Cass Avenue, Argonne, Illinois 60439

\section{December 1994}

Work sponsored by United States Department of Energy, Office of Industrial Technologies

"Smith is affiliated with Environmental Technologies Alternatives, Inc., 2511 Glen Arbor Drive, Lima, Ohio. 
बतy

This report is printed on recycled paper. 


\section{Contents}

Acknowledgments............................................................. v

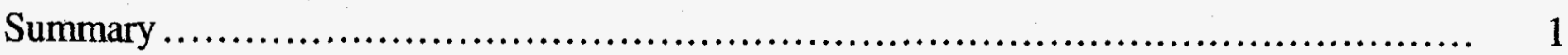

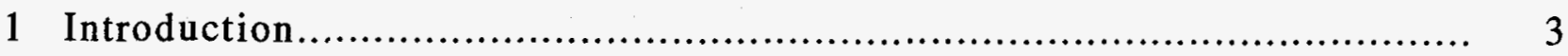

2 Development of User Interest in Product Applications ............................ 4

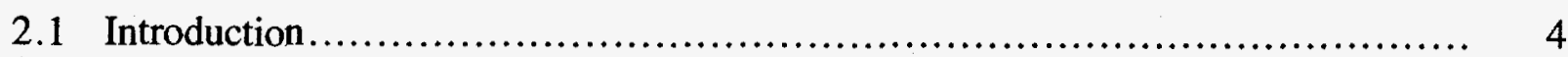

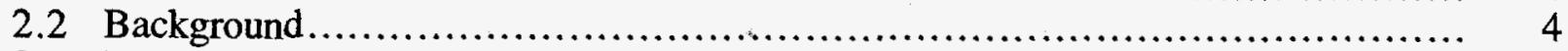

2.3 Results................................................................... 4

3 Test and Evaluation Program.................................................. 17

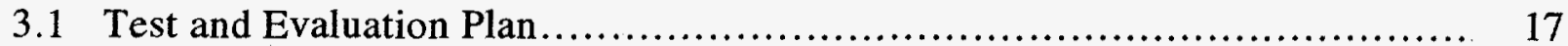

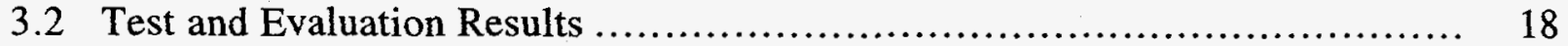

3.2.1 Footwear Applications .................................................... 18

3.2.2 Urethane Foam Applications ............................................. 39

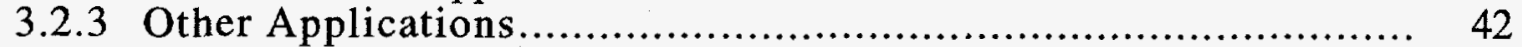

3.2 .4 Unsatisfactory Results ............................................... 55

3.2.5 Projects Referred to Air Products ........................................ 55

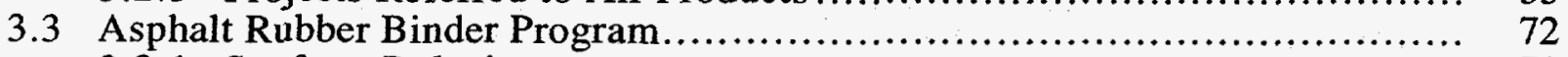

3.3.1 Surface Polarity.......................................................... $\quad 72$

3.3.2 Detailed Experimental Work Plan................................ 73

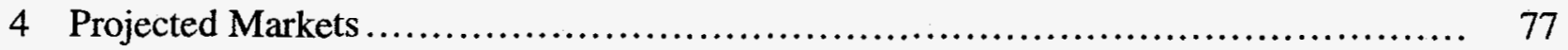

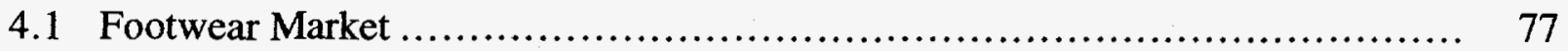

4.2 Carpet Underlay Market ...................................................... 77

4.3 Combined Footwear and Carpet Underlay Markets............................ 78

5 Conclusions and Recommendations .......................................... 79

Appendix: A Test Program for the Evaluation of Surface-Treated

Rubber as an Additive to Rubber-Modified Asphalt ...................... 81

\section{Exhibits}

2.1 Technical Fact Sheet: Surface-Modified Rubber Particles, R-4080 Series.......... 6

2.2 Companies Targeted in Original Survey ..................................... 10

2.3 Participants in Test and Evaluation Program .............................. 15

2.4 Selected Markets Defined by Product ........................................ 16

3.1 Report from Southland Industries, Inc. .................................. 20

3.2 Report from Deja, Inc. ................................................. 22 


\section{Exhibits (Cont.)}

3.3 Report from WRI/Discas....................................................... 28

3.4 Report from Foamex .......................................................... 40

3.5 Report from Miles Corporation .............................................. 43

3.6 Report from Dennis Chemical .................................................... 44

3.7 Report from Eaton Corporation.................................................. 45

3.8 Report from Ebonite International, Inc. .................................... 47

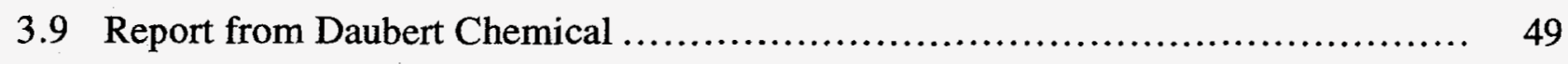

3.10 Report from Kastalon, Inc. .......................................... 50

3.11 Report from Lazerlastic Supply ............................................. 51

3.12 Report from Synthetic Surfaces, Inc. .................................... 52

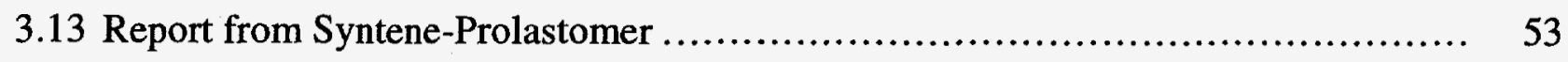

3.14 Report from Creative Materials ............................................. 54

3.15 Report from RCA Rubber................................................... 56

3.16 Report from Goodyear Tire and Rubber Company, Engineered Products - Automotive.......................................................... 61

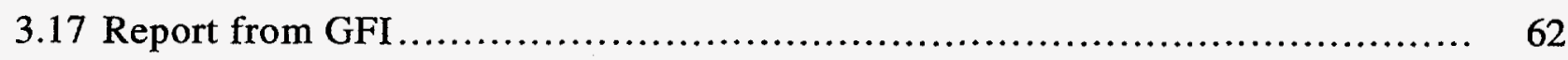

3.18 Report from Plastomer Corporation................................................. 63

3.19 Report from Bostik ........................................................ 64

3.20 Report from The H.B. Fuller Company ................................. 65

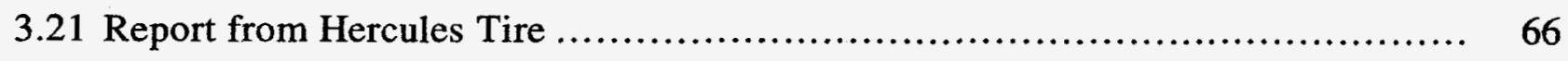

3.22 Report from Quabaug............................................................... 67

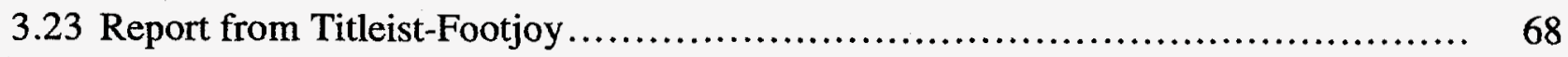

3.24 Report from Divine Bros. Company …...................................... 69

3.25 Report from Dexter Electronics........................................ 70

3.26 Special Report......................................................... 71

3.27 Report from Baker/Neste................................................. 75 


\section{Acknowledgments}

Many individuals at various companies and institutions are gratefully acknowledged for their contributions of information, material, time, equipment, and facilities. Among these individuals are the following:

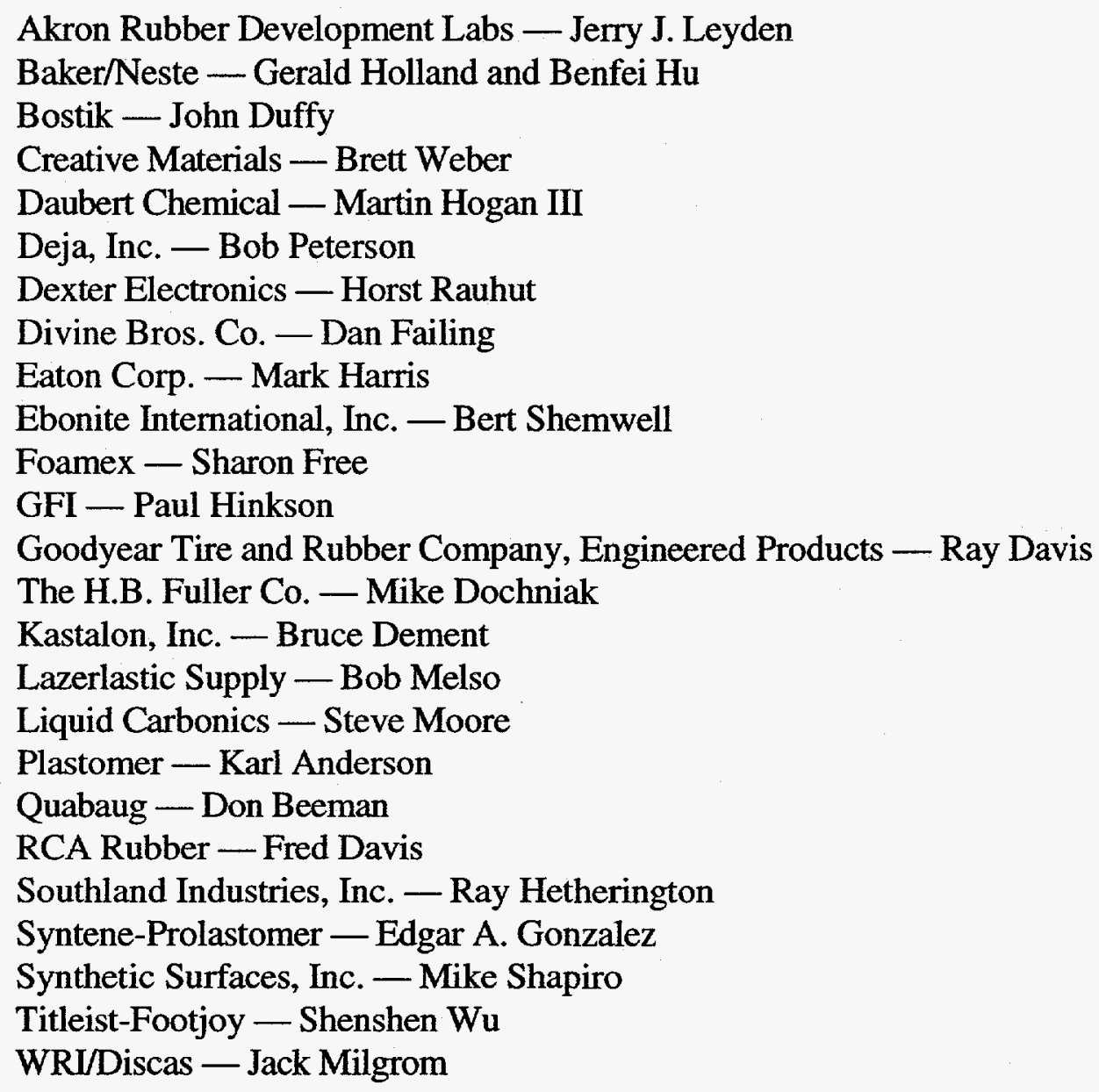

Special thanks are extended to Bernard D. Bauman of Air Products and Chemicals for his timely and essential technical support throughout our program efforts. 


\section{Utilization of Surface-Treated Rubber Particles from Waste Tires}

by

F.G. Smith*

\section{Summary}

During a 12-month program, we successfully demonstrated commercial applications for surface-treated rubber particles in two major markets: footwear (shoe soles and components) and urethane-foam carpet underlay (padding). In these markets, we have clearly demonstrated the ease of using R-4080 and R-4030 surface-treated rubber particles in existing manufacturing plants and processes and have shown that the material meets or exceeds existing standards for performance, quality, and cost-effectiveness. To produce R-4080 and R-4030, vulcanized rubber, whole-tire material is finely ground to particles of nominal 80 and 30 mesh size, respectively.

Within the market for shoe soles, we have successfully demonstrated a commercial application that would require $145 \times 10^{6} \mathrm{lb} / \mathrm{yr}$ of R-4080 surface-treated rubber particles at current levels of incorporation, which are projected to reach $300 \times 10^{6} \mathrm{lb} / \mathrm{yr}$ if ongoing research leads to higher incorporation levels. Urethane-foam carpet underlay has also been successfully produced and sold in an existing commercial-market application by using R-4030 surface-treated rubber particles. At the currently acceptable incorporation rate, this market would require a supply of up to $75 \times 10^{6} \mathrm{lb} / \mathrm{yr}$ of $\mathrm{R}-4030$ surface-treated particles.

Because of the successes achieved in these two major market applications, we can, with reasonable confidence, predict that several of the projects that are undergoing development testing and evaluations should also be successful, particularly in markets where odor-masking benefits of surface-treated rubber particles have strong marketing advantages for the customer. Therefore, it is reasonable to conclude that the market potentials demonstrated under this program exceed $500 \times 10^{6} \mathrm{lb} / \mathrm{yr}$, a projection made on the basis of the broad applications and specific industries involved in our demonstration program. We have also concluded that modifying the surface of scrap tire rubber, which enhances rubber's properties and allows treated rubber to be used as a component in polymer applications, has the potential for substantial energy savings. The modified scrap rubber may also contribute greatly to the use of postconsumer scrap-tire waste as a higher value material in polymer compounding. We also identified moisture as an area of current deficiency (the material had moisture levels of $0.8-1 \%$ ), which is curtailing the commercial success of surface-treated rubber particles in urethane-molded products. Further development is under way to correct that problem.

\footnotetext{
* Environmental Technologies Alternatives, Inc., Lima, Ohio.
} 
During Task I of our program, we also identified a number of potential users that, because of other priorities, declined to proceed within the accelerated time line required of our 12-month evaluation time frame. These companies and product applications should be pursued in a followup marketing-development effort to build on the results achieved in this program.

We believe the use of surface-treated rubber particles has the potential to significantly decrease the amount of scrap tire rubber as users become more confident about its applications. The successful use of this material, which has now begun in two major areas of high-volume commercial applications, is the basis of this belief. 


\section{Introduction}

The novel surface treatment of scrap tire rubber, developed under a cost-shared U.S. Department of Energy (DOE) contract with Air Products \& Chemicals Co., may make it possible to use large quantities of ground scrap-tire-rubber particles in diverse products. Tires are engineered to withstand severe punishment. Although several approaches exist for recovering value from scrap tires, none have demonstrated sufficient applicability or commercial viability to consume significant quantities of scrap tires. Research shows that the highest value for reused scrap tires is in applications where the recovered tire materials can be used for their material properties.

The energy savings from using surface-modified scrap tire rubber in place of virgin polymers is substantial. Making $1 \mathrm{lb}$ of surface-treated rubber particles requires only 2,000 Btu, including the energy required for grinding the tires, manufacturing and shipping the treatment chemicals, and completing the treatment process. In contrast, between 30,000 and $100,000 \mathrm{Btu}$ is required to manufacture $1 \mathrm{lb}$ of the various resins that could be substituted with treated rubber particles. Hence, energy savings of 28,000-98,000 Btu can be realized for each pound of rubber used in this way. The impact on the national energy and scrap-tire problems of using surfacetreated rubber particles will be proportional to the volume of rubber used. The market potential for surface-modified rubber particles, though far from well-defined, is thought to be substantial. On the basis of results and inferences from technical feasibility experiments, we believe that the particles can be used in all types of polymers.

In the United States, industry produces over $60 \times 10^{9} \mathrm{lb} / \mathrm{yr}$ of polymers. The amount of scrap tire rubber disposed of is $5.8 \times 10^{9} \mathrm{lb} / \mathrm{yr}$. Hence, the amount of scrap rubber available is small compared with the amount of polymers available for replacement. Also noteworthy is the likelihood that polymer resins filled with surface-treated rubber particles will be exported. Although several new uses for ground rubber crumb produced from tires are being developed (such as asphalt rubber in highways), the use of such materials in 1993 was less than $250 \times 10^{6} \mathrm{lb}$, which, at best, represents less than $10 \%$ of the scrap tires discarded annually. Untreated particles of scrap tire rubber, in crumb and powder form, are currently used as fillers in diverse applications where reduced physical properties, lower performance requirements, or other unique processing properties are desired. These applications are limited to relatively low performance requirements and are usually very price-sensitive, low-cost compounds. The value of rubber crumb in all such applications is below $\$ 0.30 / \mathrm{lb}$ and is often as low as $\$ 0.15 / \mathrm{lb}$.

Surface treatment, which is achieved by reacting particles derived from scrap tire rubber with chlorine gas, offers a new approach. With surface treatment, the rubber particles can be used in high-performance, high-cost polymer systems, which significantly increases the value and supports a selling price of $\$ 0.35-\$ 0.75 / \mathrm{lb}$ for treated rubber particles. Laboratory experiments and limited market-development activities under an Air Products/DOE cost-shared contract indicate that the material characteristics of surface-treated rubber particles warrant a focused commercial test and evaluation project, which was awarded to Environmental Technologies Alternatives (ETA), Inc., in November 1992. In this report, we identify potential end uses and describe the actual test and evaluation participants in our project. 


\section{Development of User Interest in Product Applications}

\subsection{Introduction}

Over $60 \times 10^{9} \mathrm{lb}$ of polymer are made and used in the United States annually. Surfacetreated rubber particles can be used as a cost-reducing filler when their use results in lower raw material costs. The particles can also be used as a new material for enhancing the physical properties of targeted polymers.

\subsection{Background}

To properly conduct our efforts and achieve the objectives of the program, we had to review, with Air Products, the test results and findings of work undertaken by Air Products (and others) under the ongoing DOE cost-shared contract. On the basis of that detailed review and analysis, we prepared a "technical fact sheet" on surface-modified rubber particles (Exhibit 2.1) for use in the development of our candidate product/market user interest and selection program. The new step in the process was to screen potential companies based on a profile of potential users. The list of pre-screened candidate companies included approximately 225 firms (see detailed list - Exhibit 2.2) representing broad product-market areas in which we elected to concentrate our program efforts.

The list was intentionally directed toward the manufacturers of urethane-based products in response to earlier work by a research group at Air Products. The list was then expanded to include several manufacturers of thermoplastic and thermoset rubber products in areas of polymer use most likely to be compatible with the surface-modified particulate. Because of the relatively short time of our program, we determined that a direct mailing with telemarketing follow-up would provide the early response and user participation required to meet the tightly scheduled time line of our program. The schedule required that we select participants within the initial ninety-day time frame of the program.

\subsection{Results}

Of 225 firms contacted, 198 declined to participate (favorable response rate of $11 \%$, which is considered an excellent rate). Reasons for declining to participate were as follows: the company had no interest (86); the company needed more test data and technical information to determine how best to use the material in its existing process and products (43); the company was interested, but was unable to participate and wanted to be kept informed of the results (32); the economics were not favorable (15); the company was unable to use recycled materials in its products on the 
basis of customer specifications (14); and prior evaluation of other surface treatments were unsuccessful (8).

From the single mailing, we generated favorable responses and continuing interest in an expanded test and evaluation program from 27 companies (Exhibit 2.3) and product/market applications (Exhibit 2.4). 


\section{$\operatorname{lag}_{0}$ \\ ENYIRONMENTAL \\ TECHNOLOGIES \\ ALTERNATIVES, INC}

\section{TECHNICAL FACT SHEET}

R-4080 Series

Surface-Modified Particles for use with:

Polyurethanes

Polysulfides

Expoxies

and other materials

\section{Surface Modified Rubber Particulate}

\section{R-4080 Series}

- R-4080 is produced from a vulcanized rubber whole tire material which has been finely ground to a particulate (nominal 80 mesh size) and is then surface treated using a chlorine gas to encapsulate the particle.

- R-4080 is a free-flowing black powder with a specific gravity of approximately 1.10 and a bulk density of $25 \mathrm{lbs}$.; cu.ft.

- It has excellent adhesion properties, disperses well and has exceptional surface wetting characteristics.

- Tests indicate it combines well with "polar" plastics such as polyurethane, polysulfides and acrylics. Additional trials are ongoing with other plastic and polymer materials.

- It can favorable affect hardness, toughness and dampening properties when properly introduced into formulations.

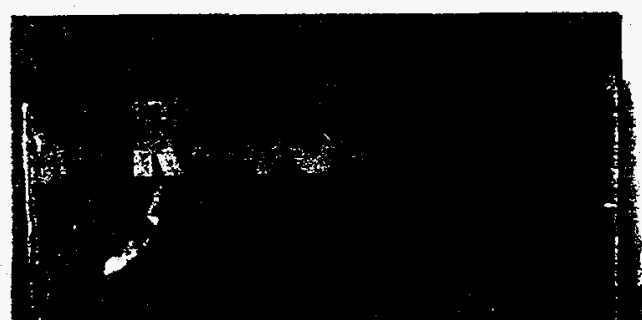

R-4080 material is currently available in trial quantities from a pilot plant facility in Pennslyvania.

For initial evaluation quantities of 1 Lb. 5 Lb. - 10 Lb. - 20 Lb. and 50 Lb. bags there is immediate delivery from stock.

Factory trial orders of 500 Lbs. or more require two weeks for delivery.

"Truck Load" quantity orders can be supplied within eight weeks of order placement.

To order:

Phone: (419) 227-3518

Fax: (419) $227 \cdot 9125$ 


\section{Introduction}

The key to this approach

is a proprietary surface-modification process that exposes finely ground particles of rubber to a reactive gas-atmosphere. This treatment increases the surface energy and adhesion properties of the rubber particles, enhancing the compatibility and bonding of the rubber to continuous-phase matrix materials.

- It affects only the outer molecular layers of each rubber particle so that one can take advantage of the inherently desirable bulk properties of the rubber.

Polar surface:

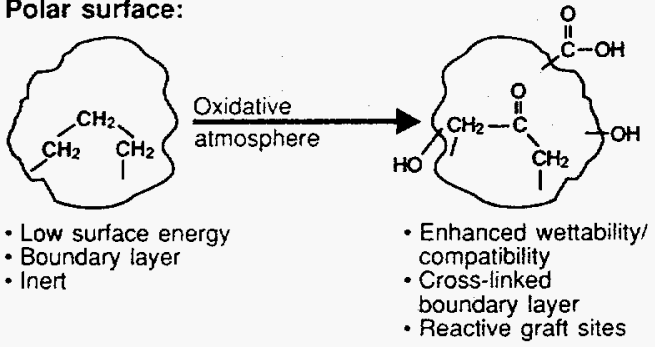

The treated rubber

could potentially be bonded with other polymers to create composites that are substantially stronger than a mere mixture of two materials. The composites could also have more versatile applications with higher value and performance.

7 he L:S. Department of Energy's (DOE) Office 1 of Industrial Technologies (OIT) sponsors research and development ( $R \& D$ ) to improve the efficiency of American industry and to provide for fuel flexibility. Working closely with industry,

OIT has successfully developed more than 25 new technologies that are saring industry about 45 trillion Btu of energy annually. Another 100 projects are in various stages of development from laboratory research to tield tests
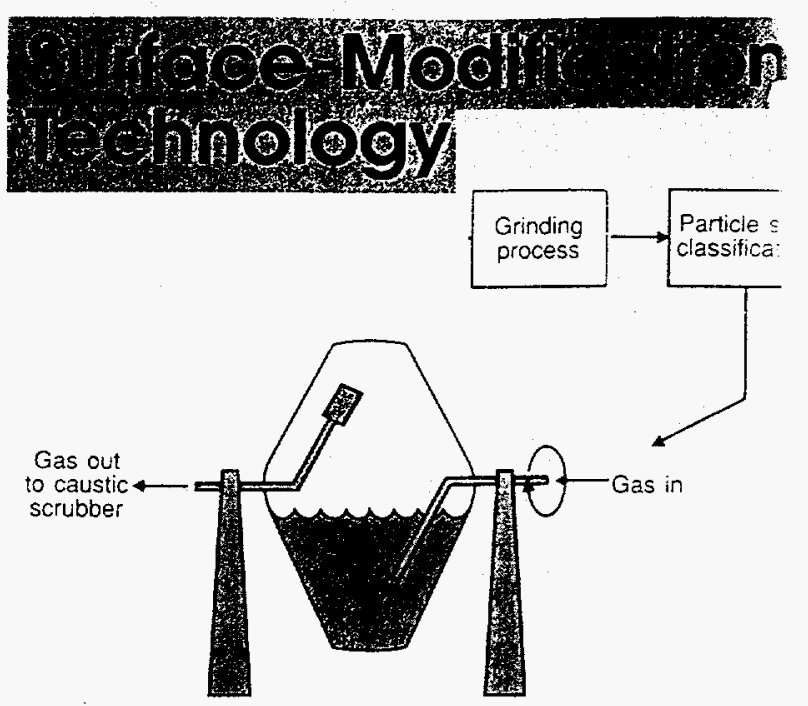

The surface-modification process is environmentally innocuous. The treatment plants can be designed to handle the reactive and toxic gases required for the process in a safe manner without adverse environmental impacts. All process chemicals are completely neutralized before they are vented to the atmosphere, and there are no solvent discharges or solid waste associated with the surface-treatment process.

The continuing R\&D efforts under way in Phase II of the project are expected to improve the cost-effectiveness of the process and to meet DOE's objective of transferring benefits of the surface-modification technology to end-users in industry.

By publishing this report, DOE seeks to disseminate the results of the project to organizations that may be interested in commercial applications of this promising technology. The report also attempts to address some of the likely concerns of these organizations regarding the new technology. Both DOE and Air Products are committed to the continuing development and eventual commercialization of the surface moditication technology. They are actively seeking and would like to hear from third parties who may be interested in using this technology, either as end-users of the treated rubber or as processors of the scrap rutber.

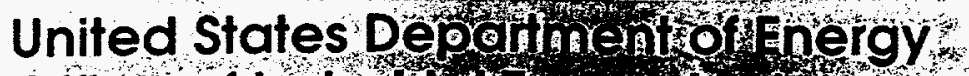 Office of IndustridTerdioloses}

Reprinted, with permission, from U.S. DOE Technical Brief. 


\section{Laboratory Tests}

As much as $40 \mathrm{wt}-\%$ of polar surface-modified rubber particles were added to cast polyurethane mixtures with little or no decrease in important physical properties. Selected properties are compared in the table for polyurethane alone (unfilled) and a composite of $15 \%$ surface-modified rubber and $85 \%$ polyurethane.

Figure 4 presents the stress-strain curves comparing an unfilled polyurethane, a $15 \%$ surfacemodified rubber-85\% polyurethane composite, and a $15 \%$ untreated rubber- $-85 \%$ polyurethane composite. This figure shows that the moduli of the treated-rubber composite and the unfilled polyurethane are virtually identical over the $0 \%$ to $100 \%$ elongation range-the useful working range of most cast polyurethanes. Thus, products made from the treated-rubber composite and the unfilled polyurethane will have essentially the same performance. In contrast, the untreated-rubber composite is much softer and more flexible. In hysteretic heating tests, unfilled polyurethanes and treatedrubber composites also gave similar performance.
Results of laboratory tests were very encouraging. For example, researchers compared the bond strengths of strips of treated and untreated rubber with polyurethane (see Figure 3). T-peel tests for polyurethane cast onto an untreated strip of rubber gave adhesion values of $3 \mathrm{lb} / \mathrm{in}$. In analogous tests with surface-modified rubber on polyurethane, the bond between the materials was so strong that the rubber itself ripped at $150 \mathrm{lb} /$ in. before the bond failed.

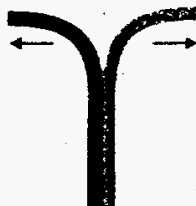

T-Peel Test Results Untreated rubber: $3 \mathrm{lb}$ in Treated rubber $>150 \mathrm{lb} / \mathrm{in}$.

Figure 3. Adhesion performance of treated and untratid rubber with polyurethane

\section{Physical Property Comparison}

\begin{tabular}{lcc}
\hline Property & $\begin{array}{c}\text { Unfilled } \\
\text { polyurethane }\end{array}$ & $\begin{array}{c}15 \% \\
\text { surface-treated } \\
\text { rubber/polyurethane }\end{array}$ \\
\hline Tensile strength (psi) & 4100 & 3500 \\
\% elongation & 278 & 275 \\
Tear resistance (Die C) & 593 & 522 \\
Tear resistance (Trouser) & 113 & 104 \\
$\%$ rebound & 49 & 48 \\
Hardness (Shore D) & 50 & 50 \\
\hline
\end{tabular}

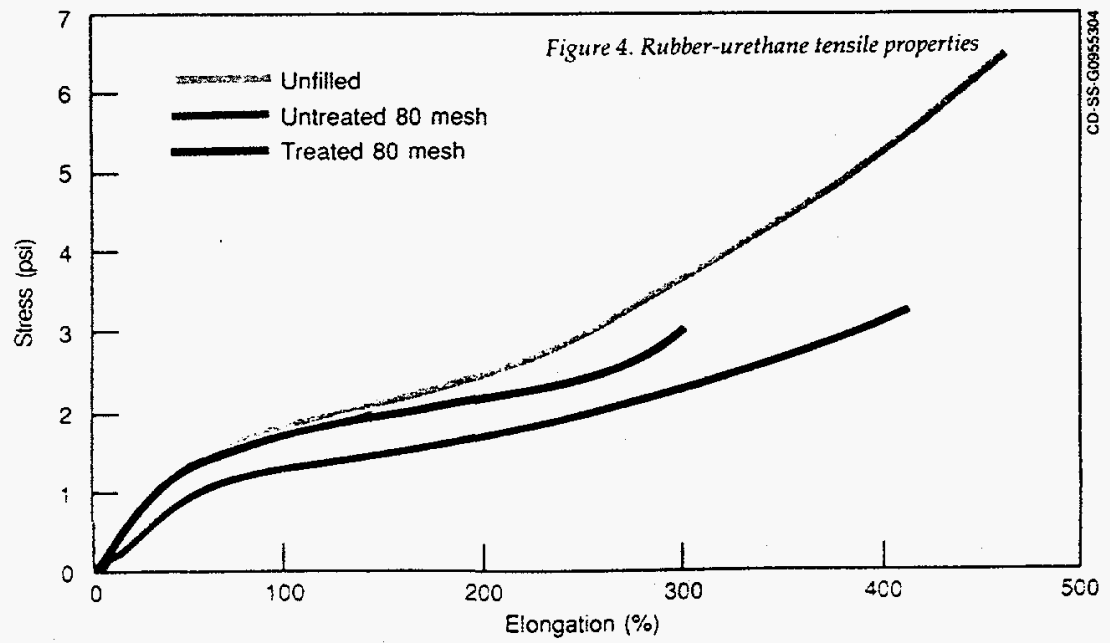

Reprinted, with permission, from U.S. DOE Technical Brief.

\section{EXHIBIT 2.1 (Cont.)}




\section{Applications and Future Work}

$S$

uccesstul laboratory tests have led Air

Products to believe that the surface-modified

rubber has exciting potential as an additive to

polymer tormulations. The treated rubber particles

can putentially be uset in the following applications:

- Cast polyurethones

- Cast epoxies

- Reaction injection-molded polyurethane

- Thermoplastic urethane

- Caulks, sealants, adhesives (based on polyurethane, silicone, epoxy, and latex)

- Coatings (based on polyurethane, epoxy, and latex)

- Foam (polyurethane and polyisocyanurate)

- Unsaturated polyesters, e.g., fiberglass

- Phenols, melamines, urea formaldehyde

- Blends or alloys with thermoplastics.

These

surface-moditied materials were added to polyurethane formulations, enhancing compatibility and adhesion. Tests showed that the physical properties of the composites varied with the following critical parameters:

- Type of polyurethane formulation used

- Weight percent loading of modified particles

- Particle shape

- Particle size distribution.
- Tires (nonpneumatic)

- Automubile fascia

- Gankets and seads

- Polvurethane shoe sole:

- Carpet underliy

- Flexiblo foam (cushions)

- Pond liners

- Conveyor belts.

- Rubberhosing

- Sheeting (panels)

- Chalk, paints, and sealants

- Adhesives

- Rollers and wheels.

The size of the ground rubber particles is a primary factor in determining how the treated material is used. For example, very finely powdered rubber is more suitable for applications requiring greater tensile strength, whereas coarserground rubber can be used for applications having other forms of reinforcement or where tensile strength is not critical. The improved performance of smaller particle sizes must be traded off against the increased cost of tire grinding and surface treatment.

\section{Further definition of}

markets for the surface-treated rubber particles depends on the physical property changes that are obtainable by the modification process. By matching material performance requirements for specific uses with cost and performance benefits, Air Products is identifying and targeting specific applications for surface-modified rubber. Several potential markets have been identified tor polar surtace-treated rubber particies in polvurethane matrices, where the greatest amiount or technical and commercial knowled ge his seen accumulated to date:

Reprinted. with permission, from U.S. DOE Technical Brief. 
COMPANY

Abba Rubber Co., Inc

Acro Products, Inc.

Acushnet Company

Aerol Company inc.

Aeroquip Corp.

AGC, Inc.

Albert Trostel Packings, Ltd.

Albion Industries

Allied Baltic Rubber, Inc.

American Fuel Cell \& Fabrics

American Roller Company

American Roller Company

Amplan, Inc.

Anchor Swan Corp.

Anderson Development

Atlantic Thermoplastics Co. Inc.

Atlos Rubber, Inc.

Beloit Manhattan

Beltservice Corp.

Boston Industrial Products

Boyd Corp.

Bruce Plastics, Inc.

Cadillac Rubber \& Plastics

Carlisle Tire \& Rubber Co.

Carolina Rubber Rolls

Century Rubber Co., Inc.

Chardon Rubber Co.

Chestnut Ridge Foam, Inc.

Clevite Elastomers

Conap, Inc.

Connecticut Rubber Molding Corp.

Cooley, Inc.

Cranz Rubber \& Gasket Inc.

Creative Urethanes, Inc.

Custom Coating, Inc.

Dataproducts Corporation

Day International

Dicar, Inc.

Dike-O-Seal, Inc.

Disogrin (aka Freudenberg-Nok)

Dodge-Regupol inc.

Dow Chemical USA

DuraQuest Inc.

Durex Products, Inc

Dynasauer Corp.

E-A-R Specialty Composites

Eagle-Pitcher Mat

Engineered Fabrics Corp.

Enterprise Rubber Inc.

Epichem, Inc.

Essex Specialty Products, Inc.

Ethyl Corporation

Exotic Rubber \& Plastics, Inc.

Fauitless Caster Corp.

\section{CITY}

Chino

Ft. Wayne

New Bedford

Los Angeles

Maumee

Meriden

Lake Geneva

Albion

Baltic

Magnolia

Union Grove

Bannockbum

Middlesex

Worthington

Adrian

Blackstone

Los Angeles

Clarks Summit

Earth City

Brentwood

Pleasanton

Pittsburgh

Cadillac

Cartisle

Greenville

Canoga Park

Chardon

Latrobe

Milan

Olean

Danielson

Pawtucket

Cheektowaga

Purcellville

Dalton

Woodland Hills

Dayton

Pine Brook

Chicago

Manchester

Lancaster

Midland

Conroe

Luck

St. Louis

Indianapolis

Willoughby

Rockmart

Akron

Bloomfield Hills

Clifton

Baton Rouge

Farmington

Evansville
STATE

CA

IN

MA

CA

$\mathrm{OH}$

CT

WI

$\mathrm{Mi}$

$\mathrm{OH}$

AR

WI

IL

NJ

$\mathrm{OH}$

MI

MA

CA

PA

MO

TN

CA

PA

MI

PA

SC

CA

OH

PA

OH

NY

CT

RI

NY

VA

GA

CA

$\mathrm{OH}$

NJ

IL

NH

PA

MI

TX

WI

MO

IN

OH

GA

$\mathrm{OH}$

MI

NJ

LA

MI

IN 
Fel-Pro, Inc.

Finzer Roller Co., Inc.

Flexaust Co.

Flexible Products Company

Foamseal, Inc.

Freeman Chemical Corp.

Furane Aerospace Products

Gallagher Corporation

Garlock

Gates Rubber Co.

Geauga Co.

Geauga Co.

GenCorp

GenCorp

GenCorp

GenCorp

GenCorp

General Latex and Chemical

General Motors Corp.

Geneva Rubber Co.

George Mann \& Co.

Globe International Inc.

Goodyear Gasket Products

Goshen Rubber Co., Inc.

Griffith Polymers, Inc.

Griffith Rubber/Bauman Hamish

Griswold Rubber Co., Inc.

Grow Group Inc.

Hercules Tire \& Rubber

Hewitt-Robins

Imco, Inc.

Industrial Roller Co.

Ingla Rubber Products

Irving B. Moore Co.

Jet Rubber Co.

JMK International Inc.

Jonal Laboratories, Inc.

JPS Elastomerics Corp.

Kent Latex Products

Lavelle Industries, Inc.

Linatex Corp. of America

Lloyd Manufacturing Corp.

Lord Corporation

Maine Rubber International

Mandrels, Inc.

Marian Rubber Products Co., Inc.

Mechanical Rubber Products Corp

Mid America Roller Co.

Minor Rubber Co., Inc.

Mitchell Rubber Products

Molded Dimensions Inc.

Mono-Thane

National Fire Hose Corp.

Nazar Rubber Company

Norh Carolina Foam Industries
Skokie

Chicago

Amesbury

Marietta

Oxford

Port Washington

Los Angeles

Gurnee

Palmyra

Elizabethtown

Middlefield

Chardon

Wabash

Fairlawn

Logansport

Marion

Berger

Ashland

Warren

Geneva

Providence

Buffalo

Davie

Goshen

Hillsboro

Garrett

Mossup

Troy

Findlay

Passaic

Huntington

Smithton

Beliflower

Cambridge

Rootstown

Ft. Worth

Meriden

Northhampton

Kent

Burlington

Gallatin

Warren

Erie

Westbrook

Louisville

Indianapolis

Warwick

Kansas City

Bloomfield

City of Industry

Port Washington

Akron

Compton

Toledo

Mt. Airy
IL

IL

GA

MI

WI

CA

IL

NY

KY

$\mathrm{OH}$

$\mathrm{OH}$

IN

$\mathrm{OH}$

IN

IN

MO

$\mathrm{OH}$

$\mathrm{OH}$

$\mathrm{OH}$

RI

NY

FL

IN

OR

IN

CT

MI

$\mathrm{OH}$

NJ

IN

IL

CA

MA

$\mathrm{OH}$

TX

CT

MA

$\mathrm{OH}$

WI

TN

RI

PA

ME

$\mathrm{OH}$

IN

NY

MO

NJ

CA

WI

$\mathrm{OH}$

$\mathrm{CA}$

$\mathrm{OH}$

NC 
O'Sullivan Corp.

Ohio Rubber Company

Oil States Industries

Page Belting Company, Inc.

Parco, Inc.

Parkway Products, Inc.

Pelmor Laboratories Inc.

Perry Chemical \& Manufacturing

Pershing Rubber Roller Corp.

Petco Inc.

Polaroid Corporation

Poly-Hi/Menasha Corp.

Polycaster Corporation

Polymer Enterprises Inc.

Polymer Enterprises Inc.

Polymer Products, Inc.

Polymer Technologies, Inc.

Preform Sealants, Inc.

Prince Rubber \& Plastics Co., Inc.

Protective Treatments, Inc.

R.C.A. Rubber Co.

Raffi \& Swanson, Inc.

Rainfair, Inc.

Red Rock Rubber, Inc.

Reed Rubber Products, Inc.

Reppenhagen Roller Corp.

Republic Roller Corp.

Rice Engineering Corp.

RM Engineered Products Inc.

Robin Industries, Inc.

Robinson Rubber Products Co..

Rodic Chemical \& Rubber Co.

RPP Corp.

Rubb Air Door Co.

Rubber \& Silicone Products

Rubber Associates, Inc

Rubber Engineering Group

Rubber Millers, Inc.

Rubber Rolls, Inc.

Rubber Rolls, Inc.

Rubber/Urethanes, Inc.

Rubber/Urethanes, Inc.

Rusco, W.J. Co.

Scandura, Inc.

Schlegal Corporation

Schroth, J.L., Co

Service Rubber Group, Inc.

Seven (7-)Sigma, Inc.

Shelley, John G. Co.

Short, Thomas A., Co.

Shreiner Sole Co., Inc.

Signal Industrial Products $\mathrm{Co}$.

Silicone Products \& Technology

South Bend Modem Molding Inc.

Sparks Belting Company

\section{Wincheser}

Willoughby

Arlington

Concord

Ontario

Cincinnati

Newton

Lafayette

Bloomfield

Lake Forest

Assonet

Ft. Wayne

Willow Street

Greensburg

Piney Flats

Grand Prairie

Detroit

Warrensville Hits

Buffalo

Dayton

Akron

Wilmington

Racine

Pella

St. Louis

Buffalo

Three Rivers

Great Bend

N. Charleston

Cleveland

Minneapolis

Kingsville

Lawrence

Ayer

Caldwell

Barberton

Salt Lake City

Baltimore

Meadowlands

Pittsburgh

Azusa

Gainesville

Akron

Chartotte

Rochester

Warten

Dallas

Minneapolis

Wellesley Hills

Oakland

Killbuck

Chattanooga

Lancaster

Mishawaka

Grand Rapids
VA

$\mathrm{OH}$

TX

$\mathrm{NH}$

CA

$\mathrm{OH}$

PA

IN

NJ

IL

MA

IN

PA

PA

TN

TX

MI

$\mathrm{OH}$

NY

$\mathrm{OH}$

$\mathrm{OH}$

MA

WI

IA

MO

NY

MI

KS

SC

$\mathrm{OH}$

MN

MD

MA

MA

NJ

$\mathrm{OH}$

UT

MD

PA

PA

$\mathrm{CA}$

TX

$\mathrm{OH}$

NC

NY

MI

TX

$M N$

MA

CA

$\mathrm{OH}$

TN

NY

IN

MI 
Sperry Rubber \& Plastics Co.Inc. Stabond Corp.

Staff Industries, Inc.

Standard Products Co.

Star-Glo Industries, Inc.

Steere Enterprises, Inc.

Steinmetz \& Sones Machinery Co.

Stern Rubber Co.

Stockwell Rubber Co., Inc.

Stowe Woodwand Co.

Sun-Tech Rubber Co.

Superior Tire \& Rubber Corp.

Superior Tire \& Rubber Corp.

Surco Inc.

Sweco, Inc.

Syracuse Rubber Products

T\& M Rubber Inc.

TACC International Corp.

Technical Rubber \& Plastic Corp.

Teknor Apex Co.

Teledyne Mono-Thane

Texacone Co.

Thombert, Inc.

Thunderline Corp.

Ton-Tex Corp.

Townley Manufacturing Co., Inc.

Trexler Rubber Co.

Tri-Seals, Inc.

Triangle Rubber Co., Inc.

Trostel, Albert, Packings, Ltd.

True Molded Rubber, Inc.

Trusty-Cook, Inc.

TSE Industries Inc.

Unarco/Duralast Rubber Products

Unique Fabricating, inc.

Uniroyal Chemical Company, Inc.

UOP, Inc.

Upaca Adhesives

Vail Rubber Works, Inc.

Vernay Laboratories, Inc.

Victor-Balata Belting

Vitofoam inc.

Wasley Products, Inc.

Weaver Industries Inc.

Westem Consolidated Technology

Westinghouse Air Brakes

Whitney Blake Co.

Wichita Falls Manufacturing, Inc.

William T. Bumett \& Co.

Williams Bowman Rubber Co.

Willow Run Rubber-Lining Co.

Winfield Industries, Inc.

Witco Corporation

Woodlawn Rubber Co.

Workman Developments, Inc.

Brookville

Gardena

Detroit

Cleveland

East Rutherford

Tallmadge

IN

Moscow

Staples

Philadelphia

Southborough

Sarasota

Warren

Warren

Hatfield

Los Angeles

Syracuse

Goshen

Rockland

Clifton

Pawtucket

Akron

Mesquite

Neston

Belleville

Grand Rapids

Candler

Ravenna

Goshen

Goshen

Lake Geneva

Los Angeles

Indianapolis

Clearwater

Tulsa

Rochester Hills

Middlebury

Des Plaines

Nashua

St. Joseph

Yellow Springs

Easton

High Point

Plainville

Denver

Goshen

Greensburg

Bellows Falls

Wichita Falls

Baltimore

Cicero

Flat Rock

Buffalo

Melrose Park

Cincinnati

Alum Creek

MI

$\mathrm{OH}$

NJ

$\mathrm{OH}$

PA

$M N$

PA

MA

$F L$

PA

PA

PA

CA

IN

. IN

MA

NJ

RI

$\mathrm{OH}$

TX

IA

MI

MI

FL

$\mathrm{OH}$

IN

IN

WI

CA

IN

FL

OK

MI

CT

IL

$\mathrm{NH}$

MI

$\mathrm{OH}$

PA

NC

CT

PA

IN

PA

VT

TX

$\mathrm{OH}$

IL

MI

NY

IL

$\mathrm{OH}$

w 
Wynn's Precision, Inc.

Yale-South Haven, Inc.
Lebanon

South Haven
TN

MI

EXHIBIT 2.2 (Cont.) 


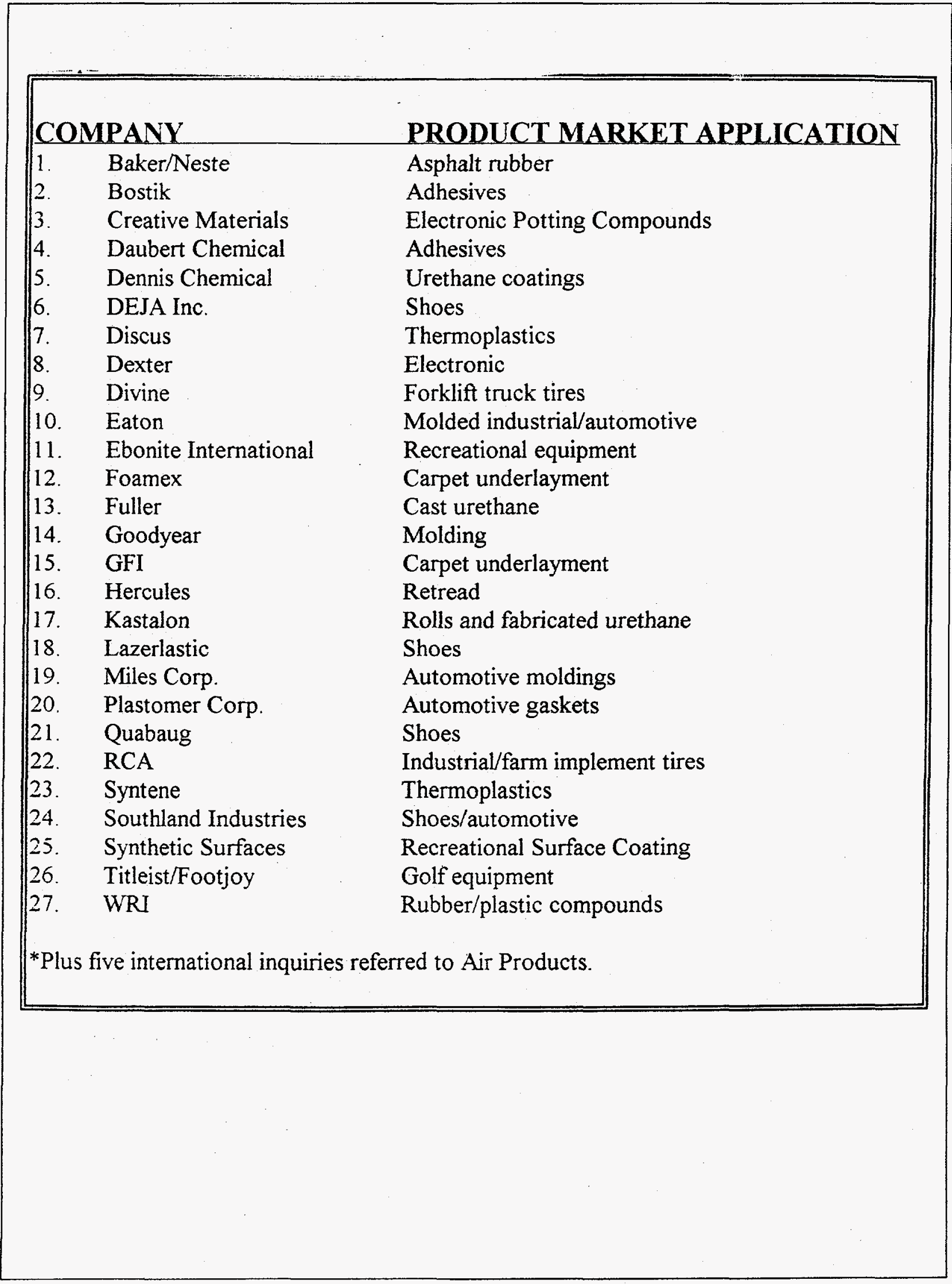




\section{MOLDED RUBBER GOODS \\ ROLLS \\ TIRES/TUBES \\ ADHESIVES \\ FOAM PRODUCTS \\ COATED FABRICS \\ FLOORING/MATS/PADS \\ ROOFING \\ HOSE \\ SHOES \\ BELTS}

URETHANE MOLDING/SPECIALTIES

AUTOMOTIVE

SPORTS SURFACES AND COATINGS

ASPHALT

ELECTRONICS 


\section{Test and Evaluation Program}

\subsection{Test and Evaluation Plan}

With each positive response from the candidate firms, we, together with the candidate firm, developed an objective for the evaluation and addressed the concerns of the individual who would be conducting the test and evaluation project. All testing and evaluation plans began with a few simple laboratory tests to determine the reaction to the surface-treated material and to observe the overall appearance of the test samples. Basic performance-measurement tests were also completed.

During this phase of the evaluation, the level at which the surface-treated material would be most suitable for incorporation into a given product was determined. Detailed discussions were focused on potential concerns about the manufacturing process, which were determined on the basis of initial laboratory test observations. In a number of cases, this interim review would result in a decision to modify the formulation or mixing conditions before undertaking additional work. These modifications sometimes required us to provide material with a different intensity. Occasionally, we had to change the mesh size of the rubber particles undergoing treatment. Also during this phase of the program, it became evident (in certain projects) that in the molding of urethane mixtures, sensitivity to moisture and resulting foaming was a critical component in the evaluation of our materials.

With a successful lab test phase completed, the next step in the evaluation program was to conduct a valid production trial. In some instances, this trial was conducted in a "pilot-sized" facility that duplicated operating conditions; in other instances, the actual factory facilities were used. The next step was to produce actual samples of the items to be fabricated and then test their performance and effectiveness. During these production trials, operating and quality assurance personnel conducted very focused evaluations and comparisons so that they could observe conditions or characteristics that, on the basis of production experience, are likely to affect efficiency, consistency of results, and quality standards. Finally, when the preceding steps were completed satisfactorily, the production samples were provided to sales, marketing (for customers' review), and final approvals.

This process must be thorough and orderly, dedicated to ensuring a confident decision to proceed with the changes required to begin producing this material in a company's products. Because this process is both lengthy and time-consuming, not all of the candidate projects were completed in the 12 months allotted to this effort under our contract. Nevertheless, we have made substantial progress with several of our candidate firms' programs; the details of that progress are well defined in Section 3.2 of this report. 
We have moved into production in two major market areas: shoe soles and urethane-foam sheet goods. We have grouped individual test and evaluation results into these broad categories:

1. Footwear applications (Section 3.2.1)

2. Urethane foam applications (Section 3.2.2)

3. Various other applications in which testing and evaluation is ongoing (Section 3.2.3)

4. Unsatisfactory results (Section 3.2.4)

5. Projects referred to Air Products (Section 3.2.5)

A special section (Section 3.3) describes the results of the asphalt rubber binder program.

\subsection{Test and Evaluation Results}

Of the 27 firms electing to proceed with test and evaluation efforts, seven were referred to Air Products because of its proximity to relevant markets and because its existing test and investigative work is related to the specific products and markets. Two firms have satisfactorily completed their initial tests and evaluations, 11 are continuing with extensive evaluation steps on the basis of successful results, and eight have concluded that they are unable to use the material in the selected application and targeted objective. In addition, four of those firms that have completed (or are nearly completed) with testing and evaluating their original program have elected to expand their level of investigation into other applications or objectives. These firms have been provided with additional materials of various mesh sizes and treatment intensities.

\subsubsection{Footwear Applications}

We have successfully concluded two shoe-sole application-development programs and are nearing the successful conclusion of two additional shoe-sole programs. Our initial success in the shoe industry was achieved in a newly formulated cork-and-rubber-molded shoe sole (see Exhibit 3.1, Southland Industries report). Similar results have been achieved with Deja Shoe (Exhibit 3.2). Each sole was made of thermoset rubber compounds, incorporating $20 \%$ R-4080 materials. Additional shoe-sole work is proceeding through WRI/Discas (Exhibit 3.3) on a thermoplastic "soft-shoe" molded sole incorporating 10\% R-5080 surface-treated particles. On the basis of extensive laboratory and factory trials, this newly developed thermoset compound, which uses surface-modified rubber particles, has been approved for production. 
Within these four separate shoe projects, we have been able to clearly demonstrate that the particles can be incorporated successfully in the manufacturing and processing of shoe soles with good overall product performance. We also have several new shoe-sole configurations that are designed for new shoe models. The goal is to produce a thermoset sole compound containing approximately $50 \%$ surface-modified particles that meet or exceed industry standards while achieving the desired cost-benefit objectives targeted for this new shoe-sole material.

A companion effort, directed toward the "softer" shoe-sole market application, is under way. This program is proceeding on a similar but expanded level of effort to develop a thermoplastic compound that incorporates up to 50\% surface-modified -80-mesh rubber. The new sole requires both variations in surface-treatment levels and sole compounds that will include special modifiers and coupling agents incorporating plastics and/or urethanes.

On the basis of these results, we have clearly determined a solidly based market potential for surface-treated materials in the shoe industry. 
FINAL REPORT:

COMPANY NAME: SOUTHLAND INDUSTRIES INC.

PRINCIPAL CONTACT: Ray Hetherington

EVALUATION OBJECTIVE:

TO FORMULATE USING POST CONSUMER RECYCLED MATERIALS A SERIES OF NEW COMPOUNDS FOR THE SHOE INDUSTRY FOR USE IN RUBBER THERMOSET MOLDING OF SHOE SOLES AND THE FABRICATION OF CERTAIN RUBBER AND CORK MATERIAL COMBINATIONS OF POST CONSUMER WASTE.

\section{BACKGROUND:}

The shoe industry has an ongoing activity to greatly increase the use of recycled materials as part of an aggressive effort to gain market share for their products. This has led them to innovative companies for material development work.

\section{TRLAL RESULTS:}

Initial laboratory trials determined that the compound objectives of "one priority product" application could be met by the incorporation of $20 \%$ of R-4080 type surface treated waste tire material in the rubber/cork compound.

Subsequent factory trials went forward without difficulty and in September 1993 a first product order for 3000 pounds of R-4080 was placed for use in the manufacture of shoe sole blanks for molding.

\section{CONCLUSION AND RECOMMENDATIONS:}

Based on this work, it is likely that surface treated post-consumer rubber materials will find a number of volume applications in the thermoset shoe industry as well as in special composite compounds in which cork is an ingredient.

\section{REFERENCES:}

See attached.

\section{REPORT DATE:}

$$
12-15-93
$$

EXHIBIT 3.1 Report from Southland Industries, Inc. 


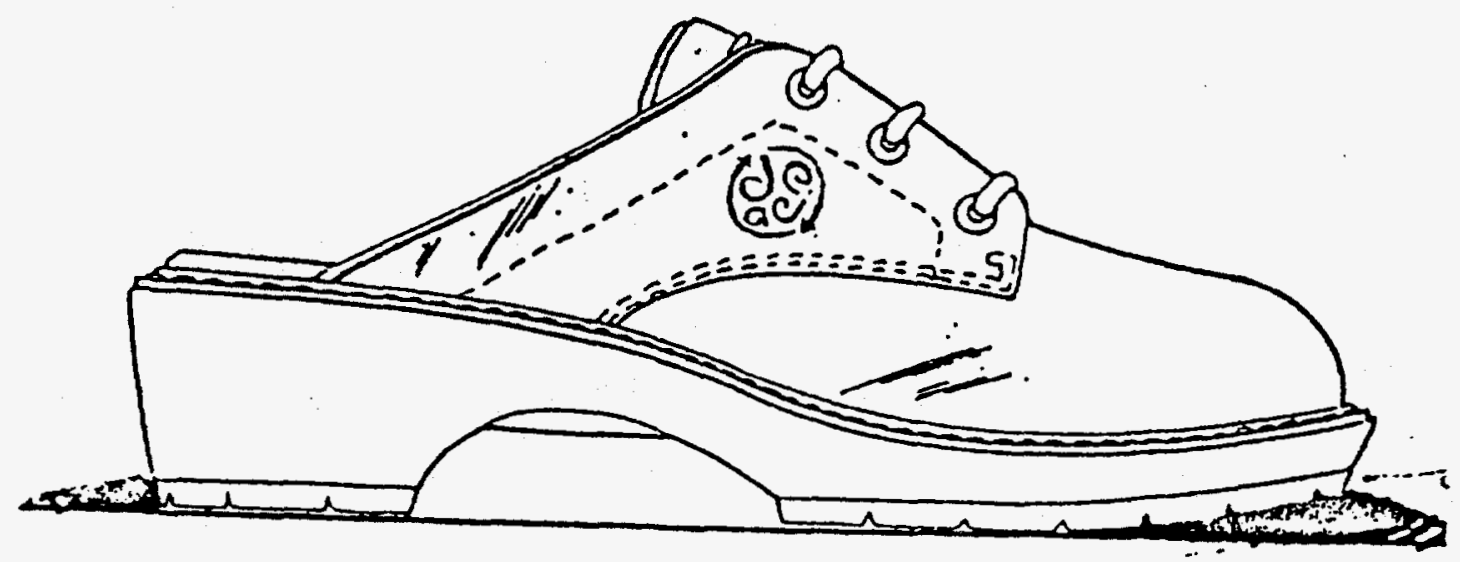

CIOGS OXFORD

S12E:

5 - 11 (Whole Sizes Only)

COLORS:

BLK (Black/Cork)

STYLE:

DNM (Denim/Black/Cork)

$520 \mathrm{WS}$

BRZ (Bronze/Black/Cork)

$520 \mathrm{WS}$

$520 \mathrm{WS}$

EXHIBIT 3.1 (Cont.) 
FINAL REPORT:

COMPANY NAME: DEJA INC.

PRINCIPAL CONTACT: Bob Peterson, Vice President Product Development

EVALUATION OBJECTIVE:

DEJA SHOE IS COMMITTED TO THE MAXIMUM USE OF RECYCLED POSTCONSUMER WASTE MATERIALS IN ALL OF THEIR PRODUCTS. UNDER THESE GUIDELINES OUR PROJECT WAS CREATED TO DETERMINE HOW BEST TO USE SURFACE TREATED SCRAP TIRE RUBBER R-4080 IN DEJA'S NEW MODEL SHOE DEVELOPMENT EFFORTS AS A POST-CONSUMER RECYCLED RUBBER MATERIAL COMPOUND INGREDIENT.

\section{BACKGROUND:}

Earlier work by DEJA with various material suppliers and compound development work had succeeded in the use of pre-consumer industrial waste rubber at levels up to $50 \%$ in shoe sole compounds. Our efforts were toward similar "post-consumer" waste incorporation levels.

\section{TRIAL RESULTS:}

See attached test program information.

\section{CONCLUSION AND RECOMMENDATIONS:}

This program has the potential for a wide assortment of shoe sole applications at incorporation rates up to $50 \%$ which would provide for significant usage of surface treated post-consumer tire rubber.

It is recommended that follow-on support and assistance be maintained with DEJA Shoe.

\section{REFERENCES:}

See attachments.

REPORT DATE:

\section{$12-15-93$}

EXHIBIT 3.2 Report from Deja, Inc. 


\section{DEJA INC.}

CONTINUED FROM PAGE 1

\section{TRIAL RESULTS:}

The initial test program centered on thermoset molding compounds in which varying amounts of R-4080 were included in test formulations in order to select other compound component adjustments in order to achieve the desired results.

This initial work has shown a definite potential for success and has been followed by two subsequent production trial shipments to companies who are preparing shoe sole samples for extensive performance tests for a broad range of characteristics which include abrasion, flex, notch and compression, all essential to meet or exceed the industries established standards for footwear shoe soles.

To date progress is satisfactory and proceeding toward a successful development. 


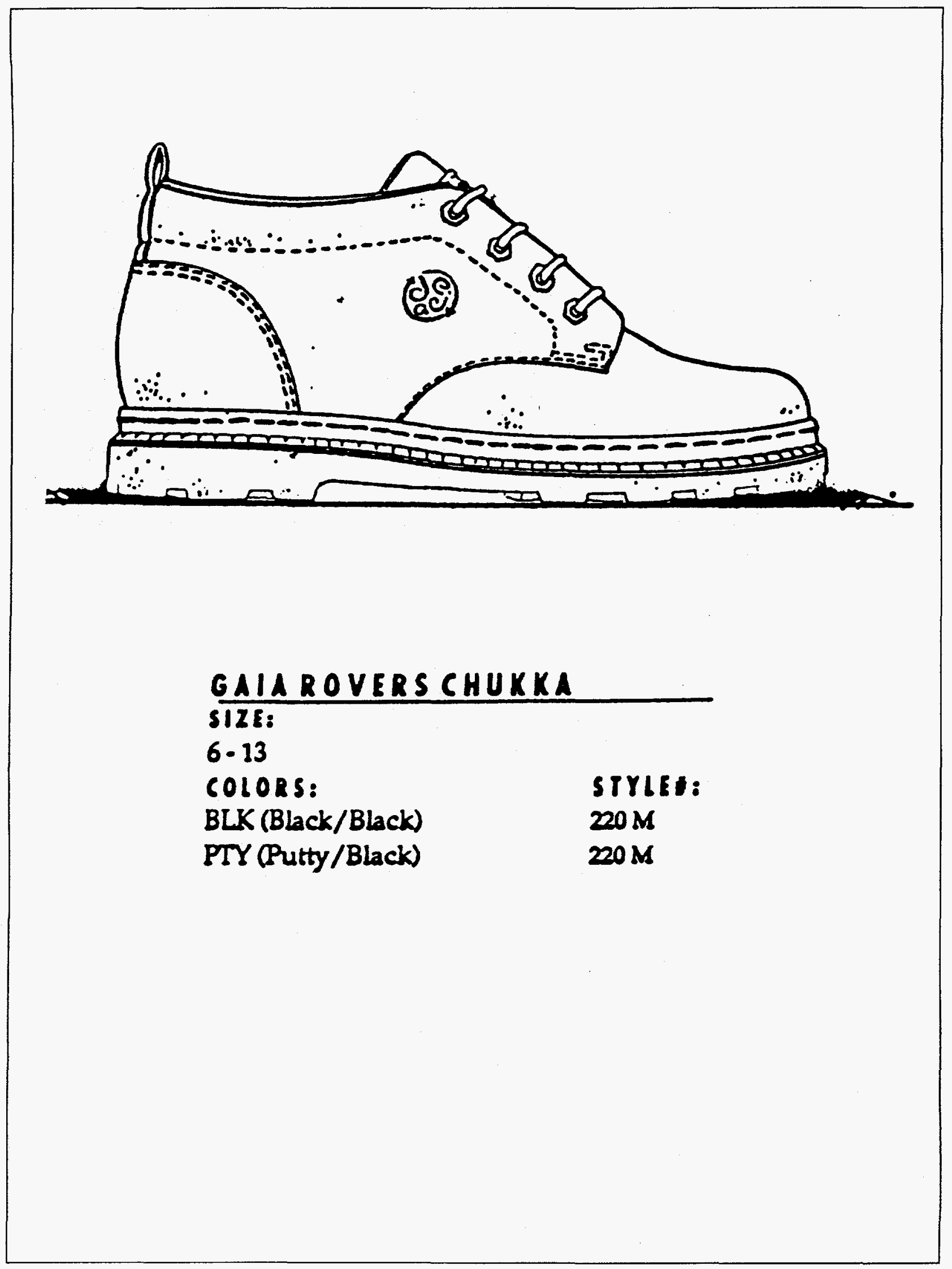

EXHIBIT 3.2 (Cont.) 
I Rubber \& Plastics Nows II - Seplember 6, 1993

\section{Deja nears goal of total earth-friendly shoe}

\section{By Bath Ann Earle}

TIGOR, Ore.-Deja Ine in ore step loser to it goal of crenting the most inviromentelly correct shoe possible. The Troar-beed firm it using a neiv uteolo componand, balf of which in recs. led phit-ongmer tire rubber. Tt's a if step," said Bob Potereon, Deja's protuction vice president

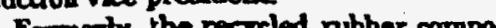
Pormerty, the regcled rubber compoent was reclaimed finen masufacturs. :rs' waste. Bnvironmentalivte place nove value on uring postconsumer to. ycted miaterials because thase products wore nively end op in landfin.

Te. will be converting all of our hoee ti (post-consumer rubber) " Peter con said But Deje shoes with aream coloned soles. will continus using the cromer mitsoles he mid.

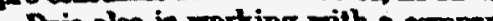
Deje aloo is working with a compan hat's developing a recycled corth - and rubter compound for the midsole in :

\section{Q y developing more sophlsticated uses for recycled materiak, we are helplng to expand the market for high-end recyclables, which is an absolute necessity for the financial siccess of the overall recycling effort. \\ - Bruce Maciregor \\ Deja inc.}

dog the thoe company is planining to release. Restaurants and wineries are turning in their old cortes from wive bottles for the project. Petersor said. That's a sort of grass-roots collection program

Aside from the tive rubber, Deje in. corporate other recriled: nubber : into its shices, induding neop tio reclaimed. firm reel anitimaters and trom gaches. manifrict manct

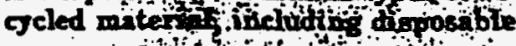

diaper arapes and wool blankets. But the company's goal isn't simply to appeal to the growing number of environ. mentally conscious consumers

-By developing mare sophisticated uses for recycled materials, we are helping to expand the market for higheod recyclablea, which-is an absolute recessity for the financial saccess of the - Drerall recycling afror " said Brace Machior Deja Preerident and CrO

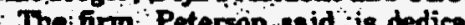
to thaloing ohoed in a propess that is the least damaging to the environment To ward that goal. Deja. like a number of rabber product makers, is turning to solvent-free adhesives.

The company also is trying to convince, ocher, langer shoe makers to we more water-based adhesives in their prodicts.

"We advocat high standards of bealth, safety and environmental pro tection in our industry," MacGregor said "We are commitued to sharing our knopledge and experience toward rnowledge and experience toward
achieving this end with ocher footwear ampanies."

Deja; which introduced its stroes thi past spring, is on track to sell mor than 100,000 pairs this year said Don Thompeon, vice president of sales The thoes are sold through spch cataloss as Thes and Nature $\mathrm{Co}$ and in lomes retein reton soros lifs Bloomingdale's and Nordstran's, as woll as through small environepental stores.

Reprinted by permission of Rubber \& Plastics News

EXHIBIT 3.2 (Cont.) 


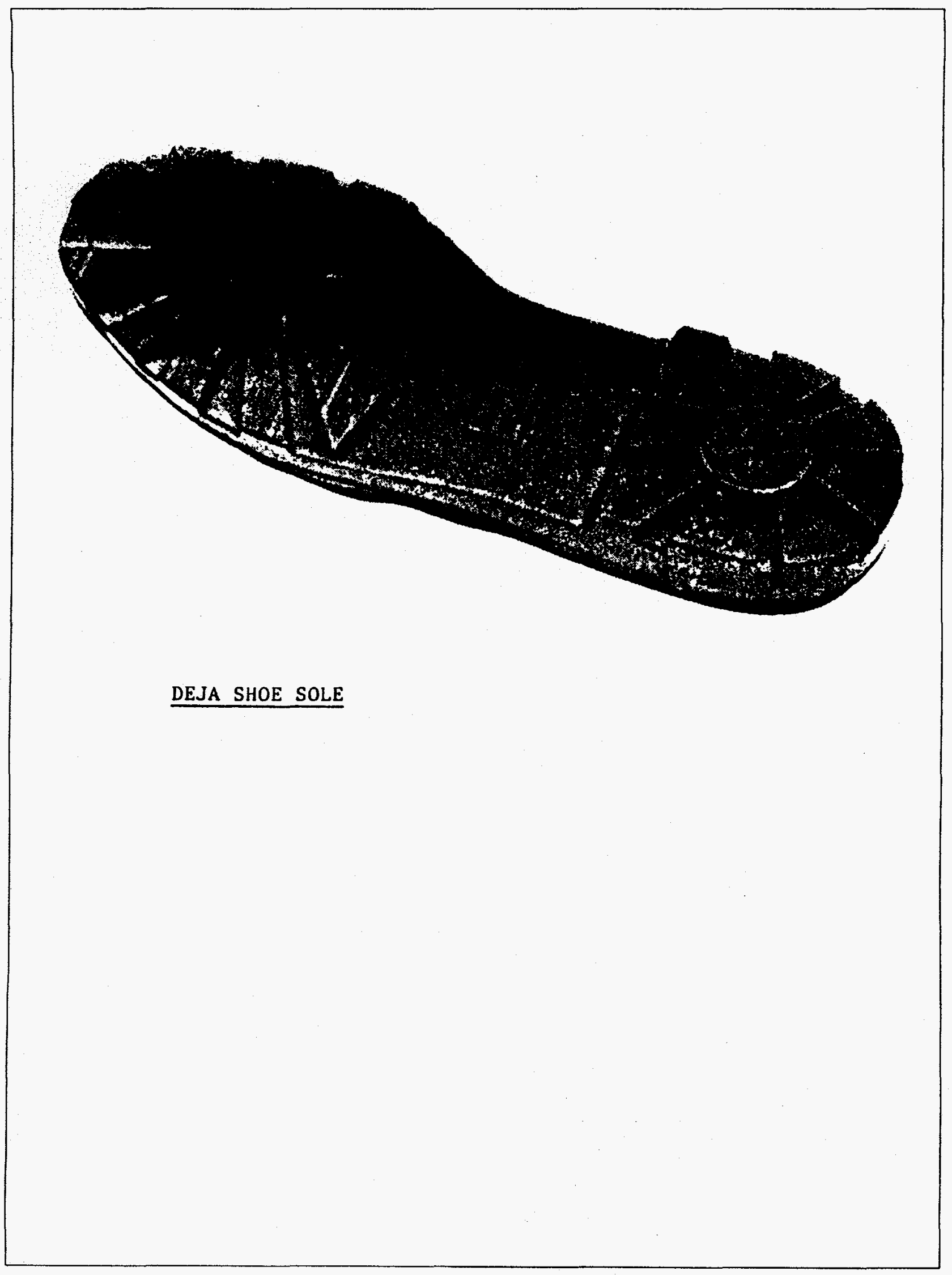

EXHIBIT 3.2 (Cont.) 


\section{WHAI'S INSILLE A UEJA SHUL!}

A closer look at DEJA's new shoes reveals a wide range of recycled materials including:

Upper/outer fabric and inner lining material in the ECO SNEAKS made from $100 \%$ recycled cotton canvas from ECO FIBRE" a new high-quality yarn spun from recovered and recycled natural and synthetic fibers.

Molded upper rubber parts constructed from $60 \%$ thermal plastic rubber, $30 \%$ of which is postconsumer recycled material from tire rubber and polystyrene coffee cups, and $30 \%$ of which is preconsumer recycled polypropylene from the tim waste during the manufacturing of diapers.

Developed by TEXON, the lasting board is made from $100 \%$ recycled fibers manufactured from reject coffee fitters and file folders.

In the ECO SNEAKS, the interfacing material between the outer fabric and the inner lining amploys:a non-woven polyester material that is $80 \%$ postconsumer recycled polyester sodá pop bottles.

Foam used in the upper collar area and tongue is $100 \%$ recycled materials from seat cushions and chairs.

The heel counter stiffener is made from trim waste from the resin materials used by other shoe makers. DEJA's supplier hạs agreed to buy back and reprocess trim waste from other shoe manufacturers on behalf of the company.

The neoprene foam cushioning attached to the lasting board is $100 \%$ praconsumer recycled trim waste from wetsuit and gasket manufacturers.

The shank board, which provides the shoe's stability, is made from $100 \%$ recycled grocery bags and corrugated cardboard.

For the outsoles, DEJA is using a naw process binding $50 \%$ preconsumer recycled rubber, destined for incineration or the landfill, with $50 \%$ virgin rubber. Research is under wayto create a material with an even higher percentage of recycled rubber.

Midsoles are $40 \%$ preconsumer recycled ethyl vinyl acetate foam made from other shoemaker's scrap, which may have otherwise gone to a landfill.

Laces are $100 \%$ cotton.

The unique DEJA shoe box is $100 \%$ recycled corrugated cardboard with water-based inks used in the printing. To encourage customers not to throw it away after purchasing the shoes, the decorative shoe box is ingeniously designed to be used as a gift box. The box is constructed so that it can be easily folded inside out, revealing beautiful etchings of rare and endangered animals.

When the shoes evertually. wear out, customers can send them back to DEJA to be recycled again. We'll encourage customers to recycle their old shoes by sending them back to us. By doing this, we can further contol the entre life cycle of our products," said Lewis.

- ECO FIBRE is a trademark of of ECO FBAE CANAOA lin. 
FINAL REPORT:

\begin{tabular}{|ll|}
\hline COMPANY NAME: & WRUDISCAS \\
PRINCIPAL CONTACT: & Jack Milgrom
\end{tabular}

\section{EVALUATION OBJECTIVE:}

TO EVALUATE THE PERFORMANCE COST BENEFITS OF SURFACE TREATED PARTICULATE FROM SCRAP TIRES IN A THERMOPLASTIC SHOE SOLE COMPOUND DEVELOPED BY DISCAS, USING RECYCLED POLYSTYRENE AND POLYURETHANE WASTE MATERIALS.

\section{BACKGROUND:}

WRI/Discas have helped develop some of the early DEJA Shoe compounds for both injected molded trim and soles and are actively engaged in the development of new commercial applications for scrap tire, rubber based TPE materials.

\section{TRIAL RESULTS:}

Physical properties were not enhanced in the existing TPU compound studied using the surface treated rubber, R-4080 and R-5080, however with certain compound modifications more favorable results were achieved*. Most significantly the "odor masking" benefit of the surface treatment was a very desirable characteristic. [ detailed reports of 11-22-93 attached]

\section{CONCLUSION AND RECOMMENDATIONS:}

In the shoe sole application, the revised compound, enriched to meet performance requirements with $10 \%$ of surface treated particulate added to the compound, providing the distinct market advantage of a greatly reduced rubber odor, with the desired postconsumer tire waste content at a targeted performance and price.

A 50 pound batch of this thermoset compound has been provided to a shoe sole manufacturer for the molding of production shoe soles for further testing and market evaluation.

\section{REFERENCES:}

See attached information.

REPORT DATE:

$$
12-15-93
$$


To: Fernley Snith (ETA)

Erom: Jack Milgrom (WRT)

Date: January 10, 1994
Subject: Progress Report--Treated Tire Rubber ( $\mathrm{Cl}-3 \%$ ) as Component of Thermoplast Shoe Sole Compounds

Ref. No. 219-01

\section{RESULTS}

The compounding procedures were the same as noted in earlier reports.

As shown in the attached table, a number of the important properties of the thermoplastic shoe sole compound containing treated tire rubber were actually inproved when the thermoplastic polyurethane (TPU) was replaced with additional SBS (styrene-butadiene block co-polymer) rubber. In the absence of TPU, compounds containing 25-29\% SBS (oil-free basis) had an elongation of $150 \%$, compared to the compound with 15\% SBS (samples AS, BT, AU, and BV compared to sample $M$ ). In our earlier studies using TPU as a component of shoe sole compounds with the treated tire rubber, the best elongation, achieved was $125 \%$. Note from the attached table that increasing the SBS content of these formulations also increased tensile and tear strength as well as the melt index of the resulting compounds containing the treated tire rubber (compare compounds $M$ with compounds AS and AU).

\section{CONCLUSIONS AND FUTURE WORK}

We believe that further increasing the concentration of SBS rubber in these TPU-free formulations will produce shoe sole compounds with adequate mechanical properies--adequate to serve selected segments of the shoe sole market. Though we have found that the themoplastic shoe sole compounds containing the treated tire rubber are slightly inferior in mechanical properties, compared to similar compounds containing the untreated tire rubber, the improved odor of the treated tire rubber compounds offers a distinct advantage, especially in a marketplace that values products with postconsumer content with all of the desirable properties of products made from virgin materials. We are confident that thermoplastic shoe sole compounds containing the treated tire rubber will find a market niche.

A manufacturer of shoe soles has been provided with some $50 \mathrm{lb}$ of a themoplastic shoe sole compound containing the treated tire rubber. This company will make available some sample quantities of shoe soles for further testing and a sample will be provided to you. 
FORMULATTONS BASED ON SBS ${ }^{\mathrm{a}}$ RUBBER

Formulation

SBS

5080 Tire Rubber ${ }^{b}$

4080 Tire Rubber

Polystyrene (Crystal)

Process Oil

Properties

$$
\text { Spectific Gravity }
$$

Shore A Hardness

Melt Index (Cond. E)

Die C Tear Strength

pli

Tensile Strength,

psi

Ultimate Elongation, \% $\frac{\text { AS }}{25.0}$

25.0

15.0

28.0

1.015

55

36

160

850

150
$\frac{\mathrm{BT}}{25.0}$

30.0

10.0

28.0

1.015

52

35

120

660

150
$\frac{\mathrm{AU}}{29.4}$

25.0

15.0

23.6

1.025

60

26

185

950

150
$\frac{\mathrm{BV}}{29.4} \quad \frac{\mathrm{M}}{15.5}$

30.0 -

25.0

$10.0 \quad 17.3$

$23.6 \quad 32.5$

$1.030 \quad 1.045$

$58 \quad 68$

$20 \quad 2.5$

$170 \quad 190$

$870 \quad 1050$

150

a Styrene/butadiene block copolymer

b Dried treated rubber

EXHIBIT 3.3 (Cont.) 
To: Fermley Smith (ETA)

Fron: Jack Milgrom (WRT)

Date: November 22, 1993
Subject: Progress Report--Treated Tire Rubber $(\mathrm{Cl}-3 \%)$ as a Component of shoe Sole Compounds

Ref. No. 219-01

\section{PROCEDURE}

Compounding procedure was the same as noted in the earlier report. Banbury mixing was done at $320^{\circ}-340^{\circ} \mathrm{F}$, and molding of test bars was done at $400^{\circ} \mathrm{F}$. RESULTS

In earlier research for commercial customers, Discas Inc. found that adding a thermoplastic polyester polyurethane to thermoplastic shoe sole corpounds at a level of 10-20\% improved mechanical properties and the general performance characteristics of these compounds. As noted in our progress report of Aug. 30 , adding tire rubber to these TPU-containing compounds invariably reduced the tear strength and elongation properties of these shoe sole compounds, but adding the treated tire rubber $(R-4080)$ reduced these properties even further.

Because of a concern that the treated tire rubber is degrading the thermoplastic polyurethane in these formulations by generating $\mathrm{HCl}$, we prepared a series of compounds with: (1) lower concentrations of tire rubber, (2) dried treated tire rubber $(\mathrm{R}-5080),(3)$ the addition of $\mathrm{CaO}$ to neutralize evolving $\mathrm{HCl}$, if that was occurring, and (4) the substitution of anhydrous silica for the hydrated silica that is normally used in these shoe sole compounds. In addition, two compositions were prepared free of TPU.

As shown in Table 1, adding tire rubber to a shoe sole compound containing TPU invariably reduces elongation but increases tensile strength and has virtually no effect on tear strength. The treated tire rubber compound behaves similarly but has even poorer elongation properties than the compound with the untreated tire rubber. Generally, a good shoe sole compound has an elongation of $300-400 \%$, a tear strength of $230-270 \mathrm{pli}$, and a tensile strength of $1100-1400 \mathrm{psi}$

Next, to determine whether $\mathrm{HCl}$ generation could be a problem with compounds containing the treated rubber and TPU, a series of formulations were prepared with anhydrous silica, $\mathrm{CaO}$, and dried treated tire rubber. As shown in Table 2, adding $1 \% \mathrm{CaO}$ to the formulation improved tear strength but had little effect on the tensile and elongation properties of the compound. Adding anhydrous silica (Celite 281) to the oried treated-tire-rubber compound decreased tear strength and elongation but hardly affected the tensile properties of the compound. 
Finally, a set of formulations were prepared with $25 \%$ treated tire rubber without TPU, as shown in Table 3. Comparing Sample M with Sample ER indicates that even in the absence of IPU, the shoe sole compound with treated tire rubber has poorer mechanical properties, compared to the similar compound with untreated tire rubber and TPU--both tear strength and elongation properties are negatively affected. Comparing samples of compounds with treated tire rubber with and without TPU (Formulations M and IR), shows, however, that the compound with TPU has poorer elongation properties and slightly poorer tensile properties.

In all instances, as noted in the attached tables, adding untreated tire rubber to the shoe sole compounds that we evaluated produced slightly more desirable compounds than when we added the treated rubber.

\section{CONCLUSIONS AND FUIURE WORK}

In sumary, the treated tire rubber shoe sole compounds with or without TPU has slightly inferior mechanical properties, compared to similar compounds containing untreated tire rubber. On the other hand, compound containing treated tire rubber had virtually no odor, compared to the similar compounds with untreated rubber. This is an important advantage. Furthermore, we expect that the compounds with treated tire rubber will have better adhesion properties.

Therefore, before halting this investigation we will prepare TPU shoe sole compounds with treated and untreated tire rubber. In place of the TPU, the concentration of SBS (styrene/butadiene block) rubber in these compounds will be increased. Until now, compounds prepared in this investigation contained 25-30\% SBS. In the future work, the concentration of SBS in these compounds will be increased to $35-45 \%$.

Finally, we will mold a shoe sole from the best compound with treated tire rubber and test it for adhesion properties and other performance properties.

\section{EXHIBIT 3.3 (Cont.)}


TABLE 1

EFFECT OF REDUCING THE CONCENIRATION OF TIRE RUBBER ${ }^{a}$

FORMULATIONS

Tire Rubber $(\mathrm{TR})^{\mathrm{b}} \quad 2080$

\& $\mathbf{~ R R}$

Hardness, Shore A

Specific Gravity

Melt Index

Die C Tear Strength

pli

12.5

65

1.035

16.0

215

Tensile Strength, psi 975

Ultimate Elongation, $\% 150$
FR

2080

25.0

65

1.050

5.5

215

1,100

100
$\underline{\mathbf{K}}$

4080

12.5

63

1.035

22.0

150

710

100
$\underline{\mathbf{R}}$

4080

25.0

65

1.050

4.0

180

1,100

50

a These formulations include a thermoplastic polyurethane (TPU), a styrene/ butadiene/styrene block copolymer (SBS) and crystal polystyrene (PS)

b 4080--Treated tire rubber ( $3 \% \mathrm{Cl}$ ), 80 mesh; 2080--Untreated tire rubber, 80 mesh 
TABLE 2

ETEDCT OF CAO \& ANHYDROUS SIIICA

ON TREATED TIRE RUBBER ${ }^{a}$

FORMULATIONS

Tire Rubber ${ }^{b}$

\% TR

$\mathrm{CaO}, \%$

Celite $281^{\mathrm{C}}$

Hardness, Shore A

Specific Gravity

Melt Index

Die C Tear Strength

pli

Tensile Strength, psi

Ultimate Elongation, \% 100
N

4080

12.5

1.0

$-$

63

1.035

24.0

195

810
$\underline{L}$

5080

12.5

$-$

added

60

1.055

44.0

135

710

50
0

$5080 \quad 4080$

$12.5 \quad 12.5$

1.0 -

added -

$60 \quad 63$

$1.055 \quad 1.035$

$40.0 \quad 22.0$

$135 \quad 150$

$600 \quad 710$

$50 \quad 100$

a The formulation include all of the conponents cited in Footnote a, Table 1

b 5080-Treated tire rubber ( $3 \% \mathrm{Cl})$, but dried

C This anhydrous silica replaced the Ultrasil that is normally used in shoe sole formulations 
TABLE 3

EFFECT OF TPU

EORMULATIONS

Tire Rubber

\% IR

TPU

$\mathrm{CaO}, \%$

Hardness, Shore A

Specific Gravity

Melt Index

Die C Tear Strength

pli

Tensile Strength, psi

Ultimate Elongation, \%
M

4080

25

$-$

-

68

1.045

2.5

190

1050

75
$\underline{\mathbf{P}}$

4080

25

-

1.0

65

1.045

4.5

195

1100

100
IR

4080

25

added

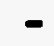

65

1.050

4.0

180

1100

50
FR

2080

25

added

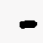

65

1.050

5.5

215

1100

100

a The formulations include SBS and PS 


\section{ETI ENMBOMMENTAL \\ Technologies \\ Alternatives, Inc. \\ Fin \\ PURCHASE ORDER}

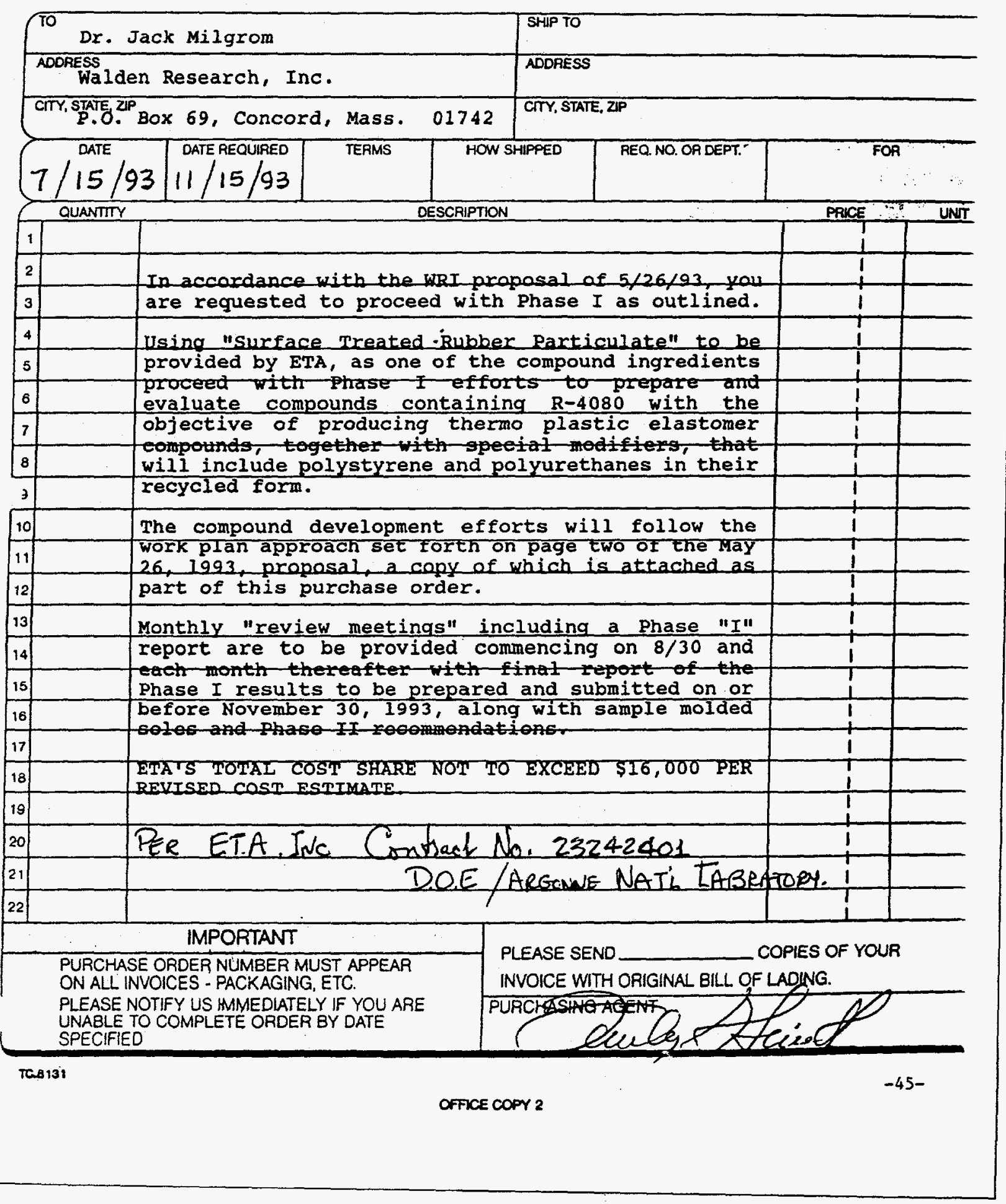

EXHIBIT 3.3 (Cont.) 
Fernley G. Smith

May 26, 1993

Page Two

APPROACH

As a thase I effort, Walden-Repar Technologies (WRT), a joint venture of Walden Research, Inc. (WRI) and the Repar Division of Discas Inc., will prepare and evaluate compounds containing the chlorine-treated scrap tire rubber. The objective is to produce thermoplastic elastomers and, therefore, the other polymers that will be used in these compounds, together with special modifiers, will include polystyrene and polyurethanes in their recycled form.

Discas Inc. now produces and sells a family of thermoplastic elastomers (TPEs) as shoe sole compounds to some of the major shoe manufacturers and is, therefore, very familiar with the needs of this end-use market. Ourrently, Discas produces some of these compounds with as much as $20-50 \%$ scrap tire rubber and uses proprietary modifiers and coupling agents.

In our Phase I"effort a series of compounds will be made using the treated rubber and the other plastic materials together with modifiers such as uncured polyurethanes. Some of these compositions will also be prepared with untreated scrap tire rubber (the same feedstock used in the treatment process). Next, the resulting compounds will be processed and molded into test bars and shoe soles in our laboratory equipment, and their properties will be measured. The key tests are abrasion resistance, adhesion to the shoe upper, delamination within the sole, tensile and elongation, tear strength, melt flow, and hardness.

Depending upon the results of the Phase I effort, the "best" compounds containing the treated rubber will be further evaluated both in-house by Discas and by some of Discas's shoe manufacturing customers in Phase II. If the further evaluations carried out in Phase II are successful, comercialization will follow. Discas Inc. could become the production and marketing arm for this new line of products. Alternatively, a variety of business arrangements are possible and can be considered.

Phase I. Compound Development--Shoe Soles

1. Prepare eight candidate compounds containing $25-50 \%$ of R-4080 Surface Treated Rubber Particulate from Scrap Tires and polystyrene, polyurethane, and other polymers, if appropriate.

2. Prepare control compounds for comparison with DOE supplied untreated R-2080 rubber particulate. Otherwise these compounds will contain the same materials at the same concentration levels prepared as cited in Item 1.

3. Perform standard tests to evaluate the mechanical and physical properties of these compounds (the list of tests are cite above) and compare them with typical sole specifications.

4. Select the compound that best meets or exceeds industry requirements and use it to mold a sample sole component in order to judge appearance and molding conditions. This sample will be used for customer evaluation.

5. Determine the comparative cost/performance benefits of the selected compound or compounds. The determination of moldability and production characteristics of the selected compound will be an essential part of this evaluation and will 
Fernley G. Smith

May 26, 1993

Page Two

\section{APRROACH}

As a Phase I effort, Walden-Repar Technologies (WRT), a joint-venture of Walden Research, Inc. (WRI) and the Repar Division of Discas Inc., will evaluate the properties of blends of the chlorine-treated scrap tire rubber and the cormodity thermoplastics cited above as well as thermoset polyurethanes and, in particular, scrap flexible polyurethanes. Special modifiers (some of then proprietary) will be used in preparing these compounds that we expect will be thermoplastic elastomers.

Discas Inc. now produces and sells a family of TPEs with recycled content as shoe sole compounds to some of the major shoe manufacturers and is, therefore, very familiar with the needs of this end-use market. Orrently, Discas produces some of these compounds with as much as $20-50 \%$ scrap tire rubber and uses proprietary modifiers or coupling agents.

In our Phase I effort a series of compounds will be made using the treated rubber and the cormodity thermoplastics and the scrap polyurethane together with modifiers, especially uncured polyurethanes. These same compositions will also be prepared with untreated scrap tire rubber (the same feedstock used in the treatment process). Next, the resulting compounds will be processed and molded into shoe soles in our laboratory equipment. The properties of the molded compounds will be measured. The key tests are abrasion resistance, adhesion to the shoe upper, delamination within the sole, tensile and elongation, tear strength, melt flow, and hardness.

Depending upon the results of the Phase I effort, the "best" compounds containing the treated rubber will be further evaluated both in-house by Discas and by some of Discas's shoe manufacturing customers in Phase II. If the further evaluations carried out in Phase II are successful, comercializtion will follow. Discas Inc. could become the production and marketing arm for this new line of products. Alternatively a variety of business arrangements are possible and can be considered.

\section{REPORTING}

At the half-way point in this program, we will review our results with you in an oral presentation. And when the program is completed, a final presentation will be made. A written report will follow. As is our usual practice, we will be in close touch with you during the course of the program by phone and FAX. 


\subsubsection{Urethane Foam Applications}

We have made excellent progress in developing applications for rubber particles in the broad market of urethane foam products. In this broad category of foam products (now undergoing testing and evaluation by various client companies), each client application had unique requirements. Generally, the testing phase focused first on the selection of the surface-treatment particles, both in terms of particle size and surface-treatment intensity. Then, the percent of incorporation was studied. At each stage of testing, while the resulting effects on physical properties (such as tensile, elongation, tear, and stiffness) were measured, appearance was observed, and likely processing problems before a full factory trial evaluation were noted.

In one such evaluation, the results were very positive (Exhibit 3.4). After extensive lab tests, surface-treated 30-mesh rubber was selected, because it had met or exceeded all client industry expectations in the laboratory. A pilot-plant trial, in which several hundred pounds of surface-treated 30-mesh rubber at the selected incorporation level were used, resulted in very acceptable product processing and a reduction in material loss (versus standard material). Overall testing of the properties exceeded the quality and technical requirements of the product.

At this point in the evaluation, a very desirable side benefit became apparent as a result of treating the surface of the rubber particles with chlorine: the chlorine either removes or masks the normal rubber odor. In this client/end-user application, the lack of any rubber odor was a strong marketing plus. With these positive results, the company scheduled a scaled-up factory trial, which incorporated several thousands of pounds of surface-treated 30-mesh rubber in a final processing and quality evaluation test, along with a confirmation of the cost benefits of incorporating the surface-modified particles.

The factory trail yielded excellent results. In terms of productivity and product yield, as well as quality and ease of processing in the existing facility (without modifications), all manufacturing cost targets were met or exceeded. The finished product has been processed according to final customer requirements. Extensive discussions with the participating company's technical, sales, marketing, and management personnel indicate considerable confidence in the product's potential for success.

On the basis of the success of this project, the client is planning to expand the evaluation of surface-treated particulate rubber in several other applications. Neither the company nor the application can be revealed by mutual agreement, because the customer is conducting heavy inhouse testing and evaluation at its expense. This foam-application program represents a very high volume market application for surface-modified rubber particles; this market is likely to equal or exceed that of the shoe-sole applications being developed. 
FINAL REPORT:

COMPANY NAME

FOAMEX

PRINCIPAL CONTACT: Sharon Free, Sr. Chemist

EVALUATION OBJECTIVE:

TO PRODUCE A FOAM URETHANE PRODUCT WITH A TARGETED MARKET

ADVANTAGE OF MMPROVED STIFFNESS PROPERTIES AND ADDED RUBBER REINFORCEMENT CHARACTERISTICS AT AN ACCEPTABLE PRICE POINT FOR CUSTOMER APPROVAL.

\section{BACKGROUND:}

Foamex had a specific customer requirement to be met and were looking at many product formulation options to meet this requirement. Our offered candidate for a special treatment level Type R-4030 for testing was very timely and of keen interest to the development team.

\section{TRIAL RESULTS:}

See attached.

\section{CONCLUSION AND RECOMMENDATIONS:}

$\mathrm{R}-4030$, with "special level of treatment" is a very viable material for the production of urethane foam products containing $20 \%$ levels of incorporation to achieve improved stiffness with rubber-reinforcement properties, without objectionable rubber odor and has clearly demonstrated that R-4030 has a high probability of success with technical, production, and marketing personnel involved in foam applications.

\section{REFERENCES:}

REPORT DATE: $12-15-93$ 


\section{FOAMEX}

CONTINUED FROM PAGE 1

\section{TRIAL RESULTS:}

This project began by a referral from GFI in April, 1993. First laboratory test work using $R-4030$ with a pre-selected surface treatment intensity level proved to be very encouraging.

Next trial moved to a "pilot line" production condition batch, using 200 pound sample at a $20 \%$ incorporation level. Results of processing were very good with totally acceptable pilot line processing. Sample products were then extensively tested for performance in comparison with other existing and experimental products.

The R-4030/20\% level product proved equal to all others and superior in "feel" and most desirable to marketing due to "feel under foot" and the lack of strong rubber odor as a result of chlorine surface treatment masking affect.

Final trials included a full scale factory production lot, using 2000 pounds of R-4030 materials and production of final product for field/customer market test and evaluation purposes.

The plant processing went very smoothly with no difficulties in processing, handling, nor plant/operator rubber odor objections or concerns. Overall factory reaction was very positive on the new material in operations.

Foamex has a very positive view of the surface treated material in their product family. 


\subsubsection{Other Applications}

Additional promising applications are being tested and evaluated, including the following: automotive-molded goods, bowling balls, spray-applied adhesive, urethane-molded rolls, thermoplastic-molded parts, synthetic surface coatings, thermoplastic elastomer compound, and electronic component potting compound (Exhibits 4.5-4.14). Because of this work's "continuing-in-progress" status, future market acceptance or uses of these applications have not been estimated.

Several of these programs require a change in the "surface treatment" to eliminate a moisture-related problem. The evaluators have worked around this problem by adding a moistureabsorbing ingredient in the current formulations, but this change offsets some of the potential cost benefits that would be needed to fully justify proceeding further with the planned evaluation and changes in product formulation.

The existing surface-treated materials have a moisture content of $0.8-1 \%$, which can cause a foaming problem when they are mixed with the urethane. Corrective steps have already been taken to reduce the moisture from the $0.8-1 \%$ level to a $0.5-0.6 \%$ level. This product is identified as R-5080 (versus the original R-4080). However, work is continuing to further reduce the moisture to a $0.2-0.3 \%$ level, which will help solve this problem and, as a result, eliminate (or greatly reduce) the need for moisture-absorbing additives.

As can be seen from the detailed reports that follow, industry is seriously interested in the material because it offers improved adhesion in both adhesive systems and coatings. 
FINAL REPORT:

COMPANY NAME: Miles Corp.

PRINCIPAL CONTACT:

\section{EVALUATION OBJECTIVE:}

For consideration in urethane rim molding development.

\section{BACKGROUND:}

This company is a major material supplier to automotive component manufacturers using foam molding technology to produce facia and other automotive parts.

TRIAL RESULTS:

This inquiry was turned over to Air Products who were already involved in a similar application with Miles Corp. (See Phase II Air Products - final report for status of this work)

\section{CONCLUSION AND RECOMMENDATIONS:}

REFERENCES:

REPORT DATE:

$$
12-15-93
$$


FINAL REPORT:

COMPANY NAME: Dennis Chemical

PRINCIPAL CONTACT: Chuck Segar

EVALUATION OBJECTIVE:

For use in urethane coatings and special compounds, as an extender and for adhesion performance evaluation.

\section{BACKGROUND:}

Urethane products related to coatings and sports surfaces are the special area of interest for this market application.

TRIAL RESULTS:

Trial results were delayed due to personnel changes but are continuing.

CONCLUSION AND RECOMMENDATIONS:

No final results available however, preliminary evaluations were promising.

\section{REFERENCES:}

\section{REPORT DATE:}

\section{$12-15-93$}

EXHIBIT 3.6 Report from Dennis Chemical 
FINAL REPORT:

COMPANY NAME:

EATON CORP.- Air Controls Division

PRINCIPAL CONTACT:

Mark Harris, Product Engineer

EVALUATION OBJECTIVE:

DURING MANUFACTURE, CURED RUBBER COMPOUND WASTE IS GENERATED. THE PURPOSE OF THIS PROGRAM IS TO DETERMINE IF SUCH WASTE CAN BE SUCCESSFULLY REINCORPORATED IN THE PRODUCT AT AN ACCEPTABLE COST WHILE MAINTAINING QUALITY, PERFORMANCE AND PROCESSING OF THE MOLDED RUBBER PRODUCT BY UTILIZING SURFACE TREATMMENT.

\section{BACKGROUND:}

To conduct this evaluation, 250 pounds of typical factory generated waste was collected and then processed "by grinding" using a cryogenic processing to a fine particle "60 mesh" and finer. This was completed and the materials generated were forwarded to CPI for "surface treatment". Due to a relocation of the surface treatment facility, this has not been possible during the time span of this contract.

\section{TRIAL RESULTS:}

Initial lab evaluation work has been completed and as a result a more extensive trial plan has been prepared. See attached.

\section{CONCLUSION AND RECOMMENDATIONS:}

This project should be pursued to a conclusion under the new contract with CPI for it represents a typical manufacturing "waste generation" problem for which surface treatment should be evaluated.

\section{REFERENCES:}

REPORT DATE: 12-15-93 


\section{EATON CORP.}

CONTINUED FROM PAGE 1

\section{TRIAL PLAN:}

Both treated and untreated ground Eaton manufacturing waste will be reformulated after laboratory trials. This work is to be conducted for Eaton by Colonial Rubber.

Upon completion of these laboratory tests and determination as to the percentage to be reincorporated, the final treatment level performance will be measured and determined.

In this application, adhesion properties of the material are critical. Initial incorporation rates will, therefore, be conservative but the goal is to reuse at the generation rate, thus eliminating waste disposal.

The annual volume of waste generation is currently at 480,000 pounds/year. 
FINAL REPORT:

COMPANY NAME: EBONITE INTERNATIONAL INC.

PRINCIPAL CONTACT: Bert Shemwell, Chemist

EVALUATION OBJECTIVE:

TO INCORPORATE R-4080 AT LEVELS SUFFICIENT TO ACHIEVE COST BENEFITS, WHILE MAINTAINING PRODUCT PERFORMANCE, FACTORY PROCESSING AND QUALITY.

\section{BACKGROUND:}

Bowling balls are highly technically designed products with unique performance properties that are constantly being improved and tested based on material and design modifications.

\section{TRIAL RESULTS:}

See attached.

\section{CONCLUSION AND RECOMMENDATIONS:}

Provide lower moisture content surface treated materials when available for further customer evaluation.

REFERENCES:

REPORT DATE:

12-15-93

EXHIBIT 3.8 Report from Ebonite International, Inc. 


\section{EBONITE INTERNATIONAL INC. CONTINUED FROM PAGE 1}

\section{TRIAL RESULTS:}

Initial laboratory test molds using R-4080 materials established the most likely formulations to be considered. A series of trials established that a $12 \%$ incorporation level in the Polyol portion of the mix would be the basis for further work. These trials also revealed a "foaming problem" which was unacceptable for quality and processing reasons.

We then modified the treatment, reducing the moisture level from approximately $.8 \%$ to $.6 \%$ and provided the revised R-5080 for trials.

While R-5080 did show some small improvement, it was nevertheless necessary to add a total of $4 \%$ of a moisture capturing additive to control foaming to an acceptable level to production mold the test bowling balls for final finish and bowling performance evaluation.

The actual production of the test bowling balls went smoothly and without difficulty. Final bowling ball finishing by sanding and polishing produced acceptable quality surface appearance products, however when bowled, the balls were not considered acceptable due to the balllane surface interface performance. It was Ebonite's preliminary conclusion that the added moisture capturing ingredient may have modified the surface, so that the ball would not "hook" adequately.

As a result of these trials, no further investigation is planned until a moisture level of $.3 \%$ can be achieved that will permit formulations without the addition of the moisture capturing additive. 
FINAL REPORT:

\begin{tabular}{|ll}
\hline COMPANY NAME: & DAUBERT CHEMICAL \\
PRINCIPAL CONTACT: & Martin Hogan III, Chief Chemist
\end{tabular}

EVALUATION OBJECTIVE:

TO IMPROVE ADHESION PERFORMANCE OF A NEW SPRAY ON

ADHESIVE SYSTEM BY THE ADDITION OF R-40200 SURFACE TREATED RUBBER.

\section{BACKGROUND:}

New system includes new adhesive formulation and new spray application equipment development.

\section{TRIAL RESULTS:}

Laboratory results using R-40200 surface treated material were acceptable, however without an "actual spray on" test, no final conclusions were possible.

\section{CONCLUSION AND RECOMMENDATIONS:}

The adhesive program testing has been delayed due to several equipment modifications necessary to obtain suitable application/coating.

\section{REFERENCES:}

\section{REPORT DATE:}

$12-15-93$

EXHIBIT 3.9 Report from Daubert Chemical 
FINAL REPORT:

COMPANY NAME: KASTALON INC.

PRINCIPAL CONTACT: Bruce Dement

EVALUATION OBJECTIVE:

THE USE OF SURFACE TREATED RUBBER, TYPE R-4030 AS A "COST SAVING" ADDITIVE IN URETHANE MOLDED GOODS.

\section{BACKGROUND:}

This company has a long history of innovation in polyurethane, dating back to the mid1960 's.

\section{TRIAL RESULTS:}

The plan was to incorporate the R-4080 at up to $50 \%$ levels in certain molded items for which a 50 pound sample was provided. Later discussions with Mr. Dement led him to request a 50 pound sample of $\mathrm{R}-4030$ for use in the planned for casting of rolls for a customer evaluation.

\section{CONCLUSION AND RECOMMENDATIONS:}

Persistent follow-up will be required to obtain feedback from this evaluation effort. As the ability to provide a surface treated material with a lower moisture content, i.e. $.3 \%$ is developed, it would be of interest to this potential user of surface treated rubber particulate.

\section{REFERENCES:}

REPORT DATE:

\section{$12-15-93$}

EXHIBIT 3.10 Report from Kastalon, Inc. 
FINAL REPORT:

COMPANY NAME: LAZERLASTIC SUPPLY

PRINCIPAL CONTACT: Bob Melso

EVALUATION OBJECTIVE:

TO DETERMINE THE POTENTIAL USE OF R-4080 MATERIAL IN A NEW
MATERIAL DEVELOPMENT FOR THERMOPLASTIC MOLDINGS OF SHOE
COMPONENTS.

\section{BACKGROUND:}

This company has supported an independent $\mathrm{R} \& \mathrm{D}$ effort directed toward the use of scrap tire rubber in thermoplastic compounds utilizing a new theory of formulation based on a solid colloid chemistry concept.

\section{TRIAL RESULTS:}

Initial trials have been positive, work is proceeding slowly, based on certain existing technology development priorities.

\section{CONCLUSION AND RECOMMENDATIONS:}

Continued contact and exploration of treatment techniques best suited to this continuing work is recommended.

REFERENCES:

REPORT DATE:

12-15-93

EXHIBIT 3.11 Report from Lazerlastic Supply 
FINAL REPORT:

COMPANY NAME: SYNTHETIC SURFACES INC.

PRINCIPAL CONTACT: Mike Shapiro, Technical Director

EVALUATION OBJECTTVE:

TO IMPROVE ADHESION OF URETHANE SURFACE COATINGS

UTILIZNG R-4080 and R-4030.

\section{BACKGROUND:}

Coatings for athletic surfaces are applied over many existing sub-strates and adhesion is an essential performance criteria of these materials.

\section{TRIAL RESULTS:}

R-4080 material addition at $60 \%$ level of incorporation vs. untreated rubber control increased viscosity to an unacceptable level. Further work on R-4030 was tried with improved viscosity. Tests revealed a better adhesion when applied to a "steel plate" used for in-house adhesion pull tests.

\section{CONCLUSION AND RECOMMENDATIONS:}

Further work with the R-4030 material is planned.

REFERENCES:

\section{REPORT DATE:}

12-15-93

EXHIBIT 3.12 Report from Synthetic Surfaces, Inc. 
FINAL REPORT:

COMPANY NAME: PRINCIPAL CONTACT:

SYNTENE-PROLASTOMER

Edgar A. Gonzalez

EVALUATION OBJECTIVE:

THE PURPOSE OF THE PROJECT WITH THIS
COMPANY WAS TO INCREASE THEIR ABILITY TO
NNCORPORATE CRUMB RUBBER BY OFFERING A
REDUCED ODOR PRODUCT TO THEIR CUSTOMERS

\section{BACKGROUND:}

This clients interest in using surface treated rubber crumb versus untreated is based on the "odor masking" quality of the chlorine treatment.

\section{TRIAL RESULTS:}

Initial trials using R-4080 standard treatment were successful insofar as the processing of the mixture of $R-4080$ and the other materials through the equipment, however the "odor masking" results while noticeably improved were not sufficiently effective to meet the "odor level" reduction sought by Syntene for its customer requirements.

\section{CONCLUSION AND RECOMMENDATIONS:}

It is recommended that a "heavier" surface treatment sample be prepared for Syntene's evaluation and that a discussion between Dr. Bauman and Edgar Gonzalez at Syntene Prolastomer is recommended before these next samples are prepared.

\section{REFERENCES:}

REPORT DATE:

$12-15-93$

EXHIBIT 3.13 Report from Syntene-Prolastomer 
FINAL REPORT:

COMPANY NAME: CREATIVE MATERIALS

PRINCIPAL CONTACT: Brett Weber, R \& D Engineer

EVALUATION OBJECTIVE:

TO DETERMINE AFFECT OF R-4080 SURFACE TREATED SCRAP

TIRE RUBBER ON POTTING AND ENCAPSULATING MATERIALS

BY COMPARING IMPACT AND THERMAL SHOCK RESISTANCE.

\section{BACKGROUND:}

Current potting compounds use liquid rubber in Epoxy formulations to achieve the desired performance results.

TRIAL RESULTS:

Initial lab tests showed promise, but the necessary trials failed to go forward as planned due to a change in personnel and other reassignments at Creative Materials.

CONCLUSION AND RECOMMENDATIONS:

A test for Rheology, Cure, Hardness and Impact using R-4080 vs. Liquid Rubber in acrylic potting compounds should be carried out by an alternate source.

REFERENCES:

REPORT DATE:

12-15-93

EXHIBIT 3.14 Report from Creative Materials 


\subsubsection{Unsatisfactory Results}

In some applications and evaluations (Exhibits 3.15-3.21), we were unable to satisfy the objective established by the user on the selected single-candidate surface-treatment material. As was discovered in many of our other evaluations, the first trial based on an existing set of conditions rarely produced satisfactory results. Often, it was necessary to change the intensity of the material-surface treatment or vary the particle size chosen and consider a process variation. Nevertheless, we feel that these failed trials have provided information useful to the future development of the material. The causes of failures are listed below:*

- Particulate size interfered with nozzle size,

- Excess moisture caused foaming and resulting porosity,

- Rubber foam was not cost-effective as a filler, and

- Viscosity adversely affected handling and pot life.

\subsubsection{Projects Referred to Air Products}

This final grouping of interested and appropriate responses to our mailings were referred to Air Products for consideration (Exhibits 3.22-3.26).

* In each case, the client was unwilling to consider any alteration to the existing formulation or operating practices or the further evaluation of other treatments or particle sizes. 
FINAL REPORT:

COMPANY NAME: R.C.A. Rubber

PRINCIPAL CONTACT: Dr. Fred Davis

EVALUATION OBJECTIVE:

To evaluate R-4080 surface treated rubber particulate material in industrial tire compound used in 8-10-12" industrial tires.

\section{BACKGROUND:}

To test and evaluate mixing, flow, molding, dimensional stability and cured physical properties to determine if surface treated material can improve abrasion resistance, fatigue resistance and overall performance of tires.

\section{TRIAL RESULTS:}

The best results were achieved with a 35 pound (Table II "C") incorporation of R-4080 in a batch weight of 470 pounds, i.e. $7.5 \%$ incorporation level, however performance in fatigue tests were $6 \%$ lower than the control, as were other significant physical properties, including tear strength and abrasion.

\section{CONCLUSION AND RECOMMENDATIONS:}

In summary, in a lightly loaded, SBR compound, the incorporation of R-4080 surface treated particulate failed to provide suitable results for this application.

\section{REFERENCES:}

REPORT DATE:

\section{$12-15-93$}


EVATUATION OF $R-4080$

RUBBER PARTICULATE IN

SEMI-PNUMATIC INDUSTRIAI TIRES

Dr. Fred Davis

RCA Rubber

EXHIBIT 3.15 (Cont.) 


\section{TABLE I}

COMPOSITION OF INDUSTRIAL TIRE COMPOUND

$\begin{array}{lrrrr} & \text { CONTROL } & A & B & C \\ \text { Whole Tire Reclaim } & 85 & 85 & 85 & 85 \\ \text { Black Masterbatch (SBR) } & 75 & 75 & 75 & 75 \\ \text { Natural Rubber } & 37 & 37 & 37 & 37 \\ \text { LX 1200 Resin } & 5 & 5 & 5 & 5 \\ \text { Stearic Acid } & 2 & 2 & 2 & 2 \\ \text { Zinc Oxide } & 3 & 3 & 3 & 3 \\ \text { Sunolite 100 Wax } & 1 & 1 & 1 & 1 \\ \text { Struktol A-60 } & 3 & 3 & 3 & 3 \\ \text { Flectol H } & 1 & 1 & 1 & 1 \\ \text { Sulfur } & 5 & 5 & 5 & 5 \\ \text { MBTS } & 1 & 1 & 1 & 1 \\ \text { Urea } & 1 & 1 & 1 & 1 \\ \text { Mineral Rubber } & 25 & 25 & 25 & 25 \\ \text { Hard Clay } & 50 & 50 & 50 & 35 \\ \text { Whiting } & 175 & 150 & 125 & 150 \\ \text { R-4080 Particuzate } & - & 25 & 50 & 35 \\ \text { Naphthenic Oif } & - & 5 & 10 & 6\end{array}$

All welghts are in pounds

EXHIBIT 3.15 (Cont.) 
TABLE II

PHYSICAL PROPERTIES

CONTROL

Tensile Strength ( $\left.1 \mathrm{~b} . / 1 \mathrm{n} .^{2}\right)$

Elongation :

Hardness (Shore A) $\left(23^{\circ} \mathrm{C}\right.$ )

Abrasion Resistance..(Taber) -

(mg./1000 cycles)

Tear Strength (Die C) (1b./In.)
950

65

82

2.3

120
A

928

66

80

2.8

100
B

c

924

69

80

2.7

94

TABLE \|\|

\section{FATIGUE TEST RESULTS}

Conditions: Load - $250 \mathrm{lbs}$, Speed $-3 \mathrm{mi} / \mathrm{hr}$, Temperature $-23^{\circ} \mathrm{C}$, $18^{\prime \prime}$ Pulley Wheel with one lug or cleat

Number cycles to fail

(10" tires, rib tread design)

CONTROL

A

62,800

59,420

B

c

semi-preumatic

62,800

46,810

59,115

All tires were mounted on steel wheels with roller bearings

EXHIBIT 3.15 (Cont.) 
RESULTS - OISCUSSION

The compounds containing surface trasted rubber particulate mixad equelly as well as the control compound not conteining the particulate. When ground rubber vulcanizates are used as fillers it is necessary to adjust the plasticlizer level upward to compensate for "dryness" of the betch.

For hard particulate fillers, there is generally an Increase In mixing tim and green strength with decrease in particle size. It is helpful to know the particle slze range and modules of the partlculate when designing a fllled compound so that the mixing time can be minimized.

The dispersion In the surface treated particulate rubber vulcanizate containing the 35 and 50 lbs. of particulate was poorer than the compound contalning $25 \mathrm{lbs}$. of the pareiculate per batch - with the $50 \mathrm{lb}$. addition of parzlculate rubber we begin to see a "grainyil appearance on the cut surfaces of the compound. The $35 \mathrm{lb}$. addition does not show the "gralny" appearance.

The addition of parelculate rubber generally will decrease the hardness of the vulcanizate when it replaces the flller. This is particularly true in compounds having heavy clay or mineral loading. Wo soe a gradual docrease in tear gtrength of the particulate containing compounds: this could be due to poor dispersion and particle size. The stress/straln propertias (tionslle strangth and elongation) have not signifleantly changed except in the compound containing the $50 \mathrm{lbs}$. of particulate rubber. The $50 \mathrm{lb}$. loading is too great for the amount of polymer in the batch.

The abrasion resistance has suffered signiflcantly with the higher loading of the partlculate rubber. Thls occurs because the rubber partlcles do not get adequately bonded to the rubber matrix. Hence - abrasive and tearing forces decach then readily,

The fatlgue test results overall were poorer than the control compound. All the fallures were the same; splic sldewalls and collapse of the traed. These type fallures are generally causad by heat bulldup.

The writer thinks that the particle size of the partlculate rubber was to large and hence the stress/strain and fat lgue propartles were not slgniflcantly improved. What role the morphology of the partlcle plays in the stress/serain properties is not clear. We have seen differences in physical properties from the three grinding processes, i.e., ambient ground, wet ambient ground, and cryogenic ground in previous work. The eryogenic ground rubber decreases the physical properties the least. Further investigations are needed to look at filler interactions in these heavily filled industrial tire compounds.72-

\section{EXHIBIT 3.15 (Cont.)}


FINAL REPORT:

\begin{tabular}{|ll|}
\hline COMPANY NAME: & Goodyear - Engineered Products-automotive \\
PRINCIPAL CONTACT: & Ray Davis \\
\hline
\end{tabular}

EVALUATION OBJECTIVE:

TO DETERMINE IF THE SURFACE TREATED R-4080 MATERIAL COULD BE UTILIZED IN AN EXISTING FOAM MOLDING OPERATION PRODUCING "AUTOMOTIVE DASHBOARDS"

\section{BACKGROUND:}

This "urethane" molding operation uses carbon black as a part of the mixing resin compound, which is fed at high pressure into a foam in place pad molding.

\section{TRIAL RESULTS:}

Laboratory tests determined that the surface treated scrap tire material could not reliably pass through an .033 orifice in the high pressure impingement nozzles.

CONCLUSION AND RECOMMENDATIONS:

After a review of the options, Goodyear declined to proceed further with the evaluation.

\section{REFERENCES:}

\section{REPORT DATE:}

\section{2-15-93}

EXHIBIT 3.16 Report from Goodyear Tire and Rubber Company, Engineered Products Automotive 
FINAL REPORT:

COMPANY NAME: G.F.I.

PRINCIPAI CONTACT: Paul Hinkson

EVALUATION OBJECTIVE:

TO DETERMINE THE AFFECT AND BENEFITS OF ADDING SURFACE TREATED SCRAP TIRE RUBBER R-4080 TO NATURAL RUBBER SPONGE CARPET UNDERLAYMENT.

\section{BACKGROUND:}

Customer had developed a variety of rubber compounds containing reclaimed rubber which provided cost and performance benefits but reclaim availability in the United States was in very short supply.

\section{TRIAL RESULTS:}

Lab test results did not show any benefit to existing product formulations, however their work with the material convinced them that a "sister division" at Foamex should be provided with surface treated material for use in urethane foam applications. This was arranged by Paul Hinkson in May, 1993.

CONCLUSION AND RECOMMENDATIONS:

\section{REFERENCES:}

\section{REPORT DATE:}

\section{2-15-93}


FINAL REPORT:

COMPANY NAME: PLASTOMER CORP.

PRINCIPAL CONTACT: Karl Anderson

\section{EVALUATION OBJECTIVE:}

To develop an automotive foam gasket material with a modified formulation to determine the cost benefit of $R-4080$ in a production formulation trial.

\section{BACKGROUND:}

High volume foam gasket manufacturing is a highly competitive and technically sophisticated manufacturing process.

\section{TRIAL RESULTS:}

Laboratory results indicated a level of between $10-20 \%$ of $R-4080$ could be added to the existing formulation without a serious loss of the essential properties of the gasket material. However, using it as a cost beneficial level interfered with the existing reaction sufficiently to require the addition of catalysts.

In the final evaluation stage, it was, therefore, determined that the reaction control limits would be affected and thus the loss of productivity due to the extended cycle time made further evaluation in production unwarranted.

\section{CONCLUSION AND RECOMMENDATIONS:}

Future work on this aspect of processing/material interface is recommended.

\section{REFERENCES:}

REPORT DATE:

\section{2-15-93}


FINAL REPORT:

COMPANY NAME:

BOSTIK

PRINCIPAL CONTACT:

John Duffy, Lab Manager

EVALUATION OBJECTIVE:

TO CONSIDER SURFACE TREATED SCRAP TIRE RUBBER, TYPE R-4080, AS A SPECIAL FILLER IN POLYURETHANE SEALANTS AND EPOXY GROUTS.

\section{BACKGROUND:}

Bostik was seeking to determine if this material could be used as an extender without altering the product performance.

TRIAL RESULTS:

In laboratory trials the tests did not provide results suitable for use in either of the product formulations considered by Bostik.

CONCLUSION AND RECOMMENDATIONS:

They declined to proceed with further samples due to other priorities in the laboratory.

\section{REFERENCES:}

\section{REPORT DATE:}

12-15-93

EXHIBIT 3.19 Report from Bostik 
FINAL REPORT:

COMPANY NAME:

The H. B. Fuller Co.

PRINCIPAL CONTACT: Mike Dochniak

EVALUATION OBJECTIVE:

\begin{tabular}{c} 
THIS IS A CAST URETHANE PROJECT \\
ATTEMPTING TO BLEND PRODUCT R-4080 \\
\hline
\end{tabular}

\section{BACKGROUND:}

TRIAL RESULTS:

In efforts to blend R-4080 with urethane, it was found they were unable to keep the particulate in suspension over an acceptable period of time due to the tendency to settle out. It was not able to be used in a cast urethane part that was the intent of the trial.

CONCLUSION AND RECOMMENDATIONS:

This company is prepared to look at other treatments and/or particle sizes but only if assurance can be given the "settling out" phenomenon can be corrected. No further work is planned at that time.

\section{REFERENCES:}

REPORT DATE:

12-15-93

EXHIBIT 3.20 Report from The H.B. Fuller Company 
FINAL REPORT:

COMPANY NAME: Hercules Tire

PRINCIPAL CONTACT: Byron E. Shank

EVALUATION OBJECTIVE:

To determine potential for use in tire tread compounds.

\section{BACKGROUND:}

This company is a producer of precured tire tread materials and has a continuing interest in product improvements related to tread performance.

TRIAL RESULTS:

Initial lab tests did not indicate the results sought in physical properties.

CONCLUSION AND RECOMMENDATIONS:

No further tests conducted and planned at this reporting.

REFERENCES:

REPORT DATE:

$12-15-93$

EXHIBIT 3.21 Report from Hercules Tire 
FINAL REPORT:

COMPANY NAME: QUABAUG

PRINCIPAL CONTACT: Don Beeman

EVALUATION OBJECTIVE:

TO DETERMINE IF CHLORINE SURFACE TREATED MATERIAL R-4080

MADE FROM SCRAP TIRE RUBBER COULD BE INCORPORATED INTO

EXISTING SHOE COMPOUND, IMPROVING ADHESION OF THE P.U. POUR IN MOLDED SHOE SOLE POCKET.

\section{BACKGROUND:}

Current processing requires chlorine surface treatment of thermoset molded shoe sole to insure proper adhesion of P.U. pour in at the shoe sole/upper assembly operation of the customer.

\section{TRIAL RESULTS:}

Initial levels of treatment of $1 \%$ were ineffective; later treatments of $3-5 \%$ were better, but not adequate.

\section{CONCLUSION AND RECOMMENDATIONS:}

This approach can be best achieved by an alternate method of chlorine surface treatment proposed by Dr. Bauman. It will be pursued directly by Dr. Bauman's group and Quabaug.

\section{REFERENCES:}

REPORT DATE:

$$
\text { 12-15-93 }
$$

EXHIBIT 3.22 Report from Quabaug 
FINAL REPORT:

COMPANY NAME: TITLEIST-FOOTJOY

PRINCIPAL CONTACT: Shenshen Wu, Research and Development

EVALUATION OBJECTIVE:

TO RENNCORPORATE MANUFACTURNG WASTE GOLF BALL

TRIM AS A SUBSTITUTE FILLER FOR OTHER INGREDIENTS.

\section{BACKGROUND:}

In the final stages of golf ball manufacture, cover trim waste containing high quality materials is generated which, if recovered, could improve production costs. An active program for evaluation of such options is under the direction of Shenshen Wu.

\section{TRIAL RESULTS:}

Cryogenic grinding of the "waste trim" to several particle sizes ranging from 30 to 50 mesh is planned and upon completion untreated particles will be evaluated and compared with surface treated particles.

\section{CONCLUSION AND RECOMMENDATIONS:}

Due to the timing of this program, ground waste became available in late September when no treatment facility was available. Rather than delay the project, Ms. Wu proceeded with the untreated ground waste and found it to be satisfactory without treatment.

REFERENCES:

REPORT DATE:

$12-15-93$

EXHIBIT 3.23 Report from Titleist-Footjoy 


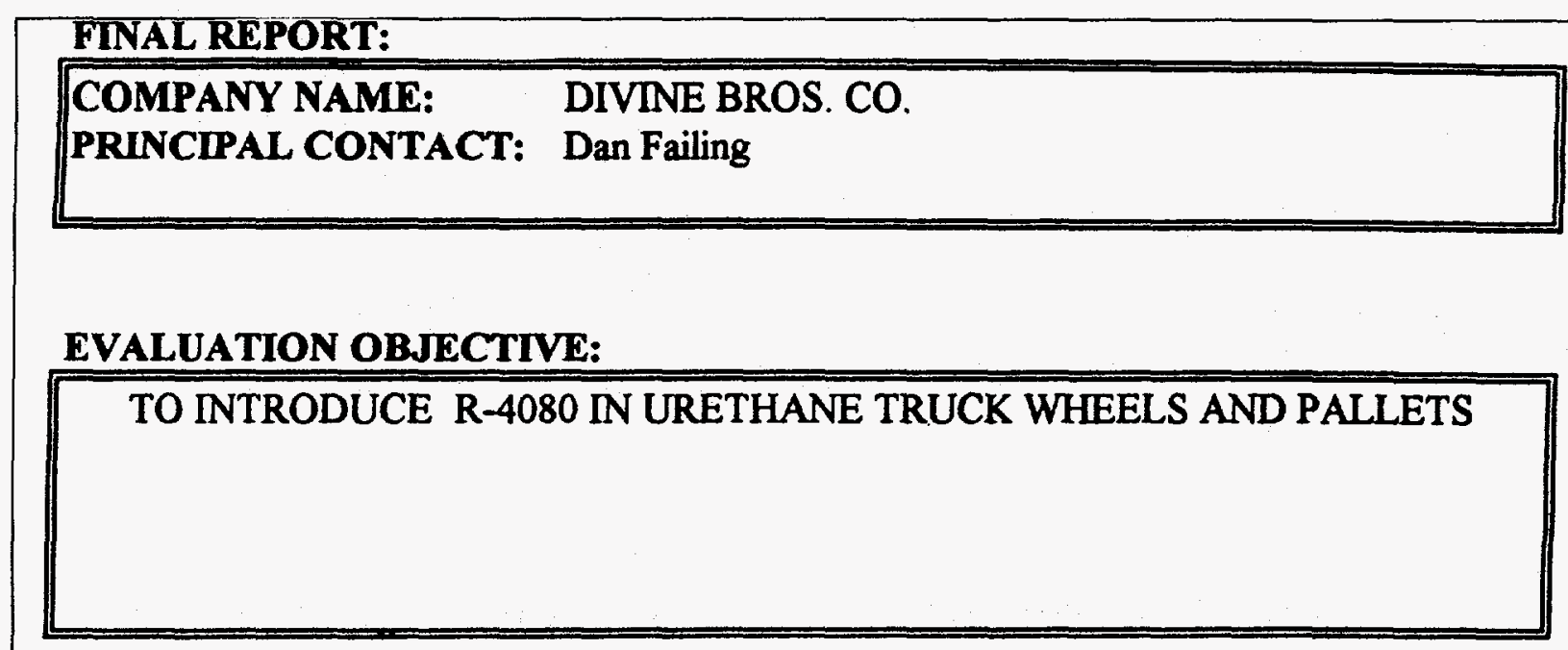

\section{BACKGROUND:}

Customer currently using a foam in place material with cost of approximately

$\$ 1.50 / \mathrm{b}$ and is seeking cost savings ideas.

\section{TRIAL RESULTS:}

This project turned over to Air Products on 3/30/93.

\section{CONCLUSION AND RECOMMENDATIONS:}

Customer requested hands on technical assistance to help evaluate the material in his application in the factory..

\section{REFERENCES:}

\section{REPORT DATE:}


FINAL REPORT:

COMPANY NAME: DEXTER ELECTRONICS

PRINCIPAL CONTACT: Dr. Horst Rauhut

EVALUATION OBJECTIVE:

USE OF SURFACE TREATED SCRAP TIRE RUBBER IN EPOXY COMPOUND INGREDIENT.

BACKGROUND:

TRIAL RESULTS:

CONCLUSION AND RECOMMENDATIONS:

This inquiry turned over to Air Products for follow up on April 21, 1993.

REFERENCES:

REPORT DATE:

12-15-93

EXHIBIT 3.25 Report from Dexter Electronics 


\section{FINAL REPORT:}

\section{SPECIAL REPORT:}

The following inquiries were not answered by ETA, but were turned over to Dr. Bauman of Air Products \& Chemicals.

\section{INTERNATIONAL RESPONSES TO OUR OUR SURFACE MODIFIED RUBBER}

1. Tebbutt Associates, England

2. Panama Poly Products PVT.LTD, India

3. Satra Footwear Technology Center, England

4. Dunlop Flooring Division, Austrailia

5. Arabian Chemical Industries, Bahrain
Adhesives

Foam

Shoes

Flooring

Expoxy \& Urethane

Sealants

REPORT DATE:

12-15-93 


\subsection{Asphalt Rubber Binder Program}

During the early stages of our program, we were approached by Baker/Neste, which had received a sample of the surface-treated rubber particulate $R-4080$. In a small and preliminary laboratory test, Baker/Neste researchers had observed a reaction indicating that the use of surfacetreated crumb-rubber-modified (CRM) component might be beneficial in the newly developing asphalt-rubber binder system, which involves the use of scrap tire rubber in highway construction. The theory and the hypothesis yielding this conclusion were related to the surface polarity defined under the Phase II development work by Air Products, which had concluded the following:

In Phase II of the project, the utility of treated tire rubber with a polar surface was explored. The treated tire rubber particles can be described as cross-linked elastomeric particles with a range of available sizes, possessing a polar surface and black in color. Market utility is then dependent on these properties as well as the economic effect of replacing virgin polymer with treated tire rubber.

\subsubsection{Surface Polarity}

The polarity of polymers has long been used to indicate the compatibility of polymers, because it is derived from the same chemical structure considerations that affect thermodynamic considerations (such as free energy of mixing) and has demonstrated general agreement with empirical results. Measures of polarity are often used as a first-order predictor of compatibility for polymer blends.

The Hildebrand solubility parameter, the simplest expression of the solubility parameter, is one measure of the polarity of a polymer that, when explored further, may include additional terms for hydrogen bonding and other effects. The Hildebrand solubility parameter is calculated as the square root of the cohesive energy density of the solvents in which the polymer shows solubility. The cohesive energy density of a solvent is the energy required to vaporize one cubic centimeter of the solvent, thereby supplying sufficient energy to overcome the forces of molecular attraction in the bulk liquid.

For surface-treated rubber, the surface solubility parameter is expected to be approximately 9.4 or higher (when additional polar groups are introduced during gas-phase surface treatment), an estimate based on the solubility parameter for chlorinated rubber. Experimental results on polyether-based polyurethanes, epoxy resins, and polysulfide elastomers have borne out this expectation. On the basis of this theory, it was concluded that the ability of surface treatment to improve the asphalt-rubber mixture's homogeneity should be more thoroughly evaluated (thus improving the consistency of the product and potentially extending the "short shelf life" of the current binder material through the use of asphalt and a scrap-tire-derived crumb-rubber additive). It was agreed to proceed with a special test program, set forth in a detailed experimental work plan, as outlined below. 


\subsubsection{Detailed Experimental Work Plan}

To compare the suspension of conventional untreated ground-rubber particles and surfacemodified (treated) ground-rubber particles mixed into asphalt, the following investigations are recommended:

a. Characterization of ground-rubber materials

1. Sieve analysis of particle-size distribution of untreated ground-rubber materials.

2. Specific surface-area measurement of ground-rubber materials (including conventional rubber and surface-treated rubber materials).

b. Preparation of control samples

1. Procure 40 mesh nonsurface-treated ground rubber (TR-40) and 80 mesh nonsurface-treated ground rubber (TR-80).

2. Mix untreated ambiently ground TR-40 rubber at low and high shear rates for $0.5,1,2$, and $3 \mathrm{~h}$ at $335-375^{\circ} \mathrm{F}$ to prepare type A rubber-modified asphalt. The weight percentages of untreated rubber are $5 \%$ and $10 \%$.

3. Mix untreated ambiently ground TR-80 rubber at low and high shear rates for $0.5,1,2$, and $3 \mathrm{~h}$ at $335-375^{\circ} \mathrm{F}$ to prepare type B rubber-modified asphalt. The weight percentages of untreated rubber are $5 \%$ and $10 \%$.

c. Preparation of study samples

1. Procure treated TR-40 and TR-80 ground-rubber surfaces by creating polarfunctional groups. This step will help to dissolve or disperse rubber in asphalt and allow it to remain in suspension.

2. Mix surface-treated TR-40 ground rubber at low and high shear rates for $0.5,1,2$, and $3 \mathrm{~h}$ at $335-375^{\circ} \mathrm{F}$ to prepare type C rubber-modified asphalt. The weight percentages of treated rubber are $5 \%$ and $10 \%$.

3. Mix surface-modified TR- 80 ground rubber at low and high shear rates for $0.5,1,2$, and $3 \mathrm{~h}$ at $335-375^{\circ} \mathrm{F}$ to prepare type D rubber-modified asphalt. The weight percentages of treated rubber are $5 \%$ and $10 \%$. 
d. Testing of rubber-modified asphalts

1. Store the previously prepared types A, B, C, and D asphalts under conditions similar to those in actual field applications.

2. Test the absolute viscosities of types A, B, C, and D asphalts at storage times of $0.5,2,4,8,24$, and $72 \mathrm{~h}$ to monitor the viscosity changes. The test procedure ASTM D2171 will be used for testing asphalt viscosity by means of vacuum capillary viscometer.

3. For each test, at least three parallel tests for each of the four types of material should be conducted in order to obtain reliable test data. According to the viscosity changes (measured by using ASTM D2171), we can compare the stabilities of conventional rubber and surface-modified rubber dissolved/or suspended in asphalt.

However, on the basis of extensive tests conducted and detailed in the Appendix, we were unable to improve the stability of the rubber-particle suspension in the asphalt-binder mixture. Upon review of the results, it was decided to close out the evaluation of surface-treating particles with chlorine. 
FINAL REPORT:

COMPANY NAME: BAKER/NESTE

PRINCIPAL CONTACT: Gerald Holland, Vice President

Benfei Hu

EVALUATION OBJECTIVE:

TO DETERMINE THE AFFECT ON "SHELF LIFE" (holding time of the asphalt rubber binder) BY DECREASING THE TENDENCY FOR RUBBER CRUMB TO SETTLE OUT OF A HOMOGENEOUS MIXED STATE WHEN COMBINED WITH ASPHALT TO PRODUCE ASPHALT RUBBER BINDER FOR USE IN ASPHALTIC CONCRETE IN ROAD CONSTRUCTION

\section{BACKGROUND:}

Asphalt rubber binder, using crumb rubber produced from scrap tires is receiving expanded consideration by highway engineers. One current problem affecting cost, construction procedures and quality; is the inability to develop a homogenous and stable mixture of crumb rubber and asphalt that can be "held" awaiting construction use for up to 48 hours and continue to maintain the consistency required of the binder.

\section{TRIAL RESULTS:}

Tests were conducted using a common and widely used A20 grade asphalt and four types of treated and untreated rubber crumb. See attached detail.

\section{CONCLUSION AND RECOMMENDATIONS:}

The more extensive tests conducted as reported in the detailed study attached, do not support the surface treatment theory that the polar asphaltines with the chlorine treated rubber crumb polar surface, would result in an improved homogenous mixture of asphalt rubber.

\section{REFERENCES:}

See attached information.

REPORT DATE:

$$
12-15-93
$$




\section{BAKERNASTE CONTINUED FROM PAGE 1}

\section{TEST AND TRIAL REPORTS CONTINUED:}

This test program encompasses the physical and chemical analysis of ground rubber materials, mixing ground rubber materials (surface treated and non-surface treated ground rubber) into asphalt and the evaluation of storage stability of the rubber modified asphalt. The physical analysis of the ground rubber materials includes particle size distribution analysis and specific surface area measurement. The chemical analysis includes the acetone extract, ash, carbon black, natural rubber, moisture and rubber hydrocarbon content tests.

In mixing ground rubber into an $\mathrm{AC}-20$ asphalt, four types of rubber were used. They were 40 mesh non-surface treated ground rubber, 40 mesh surface treated ground rubber by chlorine gas, 80 mesh non-surface treated ground rubber and 80 mesh surface treated rubber by chlorine gas. The viscosity of the rubber modified asphalt was checked at various time periods of storage to assess the degree of stability of rubber particles suspended in the asphalt.

The test program has included the physical and chemical analysis of some chosen ground rubber materials including surface treated and untreated materials. The particle size analysis shows that surface treatment possibly acts like a lubrication effect to break down the agglomerates to give slightly finer particle size distribution. The data of specific surface area shows that surface treated rubber has a little larger surface area. The results of chemical analysis shows that acetone extract increased after surface treatment.

We have measured the separation values of the rubber modified asphalt and pure asphalt for different times of storage. The separation value shows that for the rubber modified asphalt, no matter whether the rubber is 40 mesh or 80 mesh, no matter whether the rubber is surface treated or untreated, after 6 hours of storage, serious separation phenomenon were observed. Industry is typically looking for storage time measured in days rather than just hours. The separation value of the asphalt mixed with the surface treated rubber is greater than that of the asphalt mixed with the untreated rubber. This means the surface treatment using chlorine has not improved the storage stability of rubber in asphalt. 


\section{Projected Markets}

\subsection{Footwear Market}

On the basis of information gleaned from Footwear Industries of America reports and additional information received from the various shoe-sole producers involved in our program, we have estimated U.S. shoe sales to be 1,300 million pairs. Of these shoes, an estimated 585 million pairs will have thermoplastic soles, 455 million will have vulcanized rubber soles, and 260 million pairs will have leather soles. Of the total pairs sold, 470 million pairs will be casual shoes (80\%) with thermoplastic soles, and 340 million pairs (80\%) will be casual shoes with vulcanized-rubber soles.

On the basis of the results achieved to date, we believe a $20 \%$ incorporation rate is a realistic basis for projecting the market utility of surface-treated rubber material in shoe soles. Therefore, we have assumed that 470 million casual pairs with thermoplastic soles and 340 million casual pairs with thermoset vulcanized soles (with an average sole weight of $0.9 \mathrm{lb} /$ pair) equals a total polymer requirement of $729 \times 10^{6} \mathrm{lb} / \mathrm{yr}$.

If a $20 \%$ incorporation is applied, then the market potential for the use of surface-treated rubber is approximately $145 \times 10^{6} \mathrm{lb} / \mathrm{yr}$. The selling price of material Type R-4080, shipped for use in the current shoe-sole program, has been set at $\$ 0.65 / \mathrm{lb}$.

\subsection{Carpet Underlay Market}

In 1992 , the total cast urethane foam market was reportedly $1.7 \times 10^{9} \mathrm{lb}$. Of this total, carpet underlay was $373 \times 10^{6} \mathrm{lb}$. With the demonstrated properties and cost benefits of the surface-treated material in this application at a $20 \%$ incorporation rate, the estimated market utility of R-4030 type material is approximately $75 \times 10^{6} \mathrm{lb}$. It is important to note, however, that a substantial level of re-bond carpet underlay is being sold; we were unable to obtain a qualified estimate of this market. But with respect to the quality and applications for re-bond, the product using R-4030 is clearly a superior material, with uniform stiffness and rubber-reinforcing properties that should place it in a price point-marketing niche above re-bond carpet underlay grades.

For this report, we are estimating a $20 \%$ market share and a $20 \%$ incorporation rate. We would, therefore, project an actual market-utility use rate of $15 \times 10^{6} \mathrm{lb} / \mathrm{yr}$. The selling price of material Type R-4030 in truckload quantities is currently set at $\$ 0.50 / \mathrm{hb}$. 


\subsection{Combined Footwear and Carpet Underlay Markets}

The combined market utility of surface-treated material in these applications at the demonstrated use rates is $145 \times 10^{6} \mathrm{lb} / \mathrm{yr}$ in shoe soles and $75 \times 10^{6} \mathrm{lb} / \mathrm{yr}$ in cast-urethane foam material (for an overall total usage potential of $220 \times 10^{6} \mathrm{lb} / \mathrm{yr}$ ). We have other applications in process that will increase this projection, but the current status of testing and evaluation makes such projections premature at this time. 


\section{Conclusions and Recommendations}

In a 12-month period, we have demonstrated that this material can be used cost-effectively in several existing production facilities and processes, as well as in the production of consumer products (urethane foam goods and thermoset comfort shoe soles) representing two distinctly different but major markets. In the process of our work, we have also identified an important and unique characteristic of this material: its ability to mask the scrap tire rubber odor that, in consumer-related applications and in factory processing, can be a serious negative factor affecting the acceptance of recycling of rubber products. In addition, we have been able to define the need for the future development of a material with much lower moisture content than that of R-5080 to permit a greater potential for success in urethane-molded products.

Finally, for the continued commercial success of this new material (in addition to developments in surface-coating techniques and innovations in treatment technologies), decreasing the cost of supplying the ground-rubber raw material should be emphasized to ensure a broaderbased interest in this material by the polymer industry. 
Appendix:

A Test Program for the Evaluation of Surface-Treated Rubber as an Additive to Rubber-Modified Asphalt 
A SUMMARY REPORT OF THE D. O. E. PROJECT (NO. 23242401)

A TEST PROGRAM FOR THE EVALUATION OF SURFACE TREATED RUBBER AS AN ADDITIVE TO RUBBER MODIFIED ASPHALT

REPORT TO: ENVIRONMENTAL TECHNOLOGIES ALTERNATIVES, INC.

PREPARED BY: BAKER RUBBER INC.

BENFEI HU - EXPERIMENTER

GERALD W. HOLLAND - ADMINISTRATOR

NOVEMBER 29, 1993 


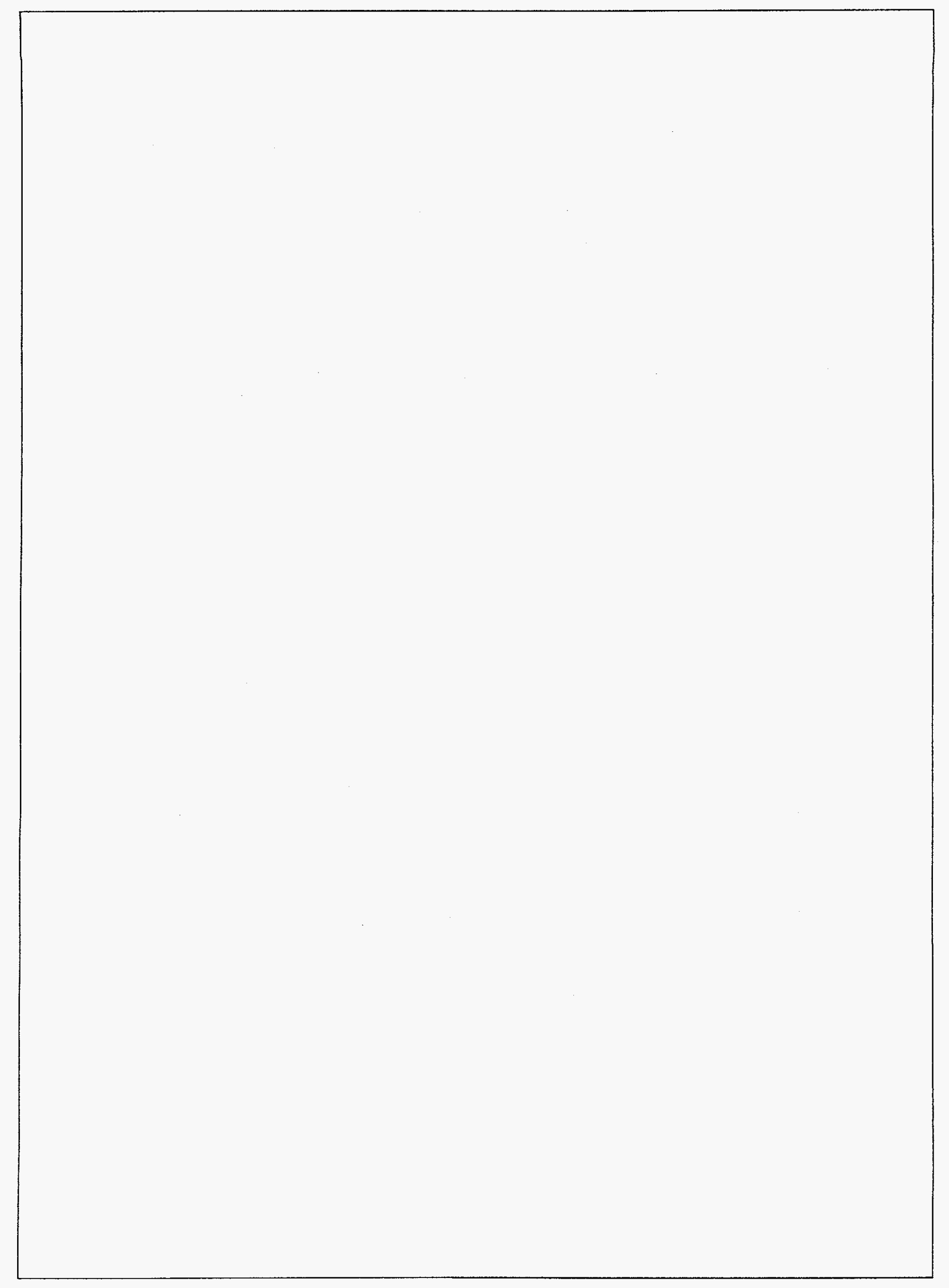


TABLE OF CONTENTS

CONTENT

PAGE

EXECUTIVE SUMMARY . . . . . . . . . . . . . . . . . 3 CONCLUSION . . . . . . . . . . . . . . . . . . . . . . 4

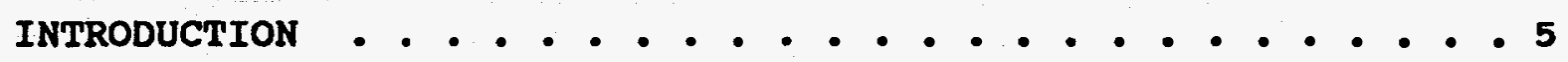
PHYSICAL AND CHEMICAL CHARACTERIZATIONS OF MATERIALS • . . . . 6 I. Ground Rubber Materials . . . . . . . . . . . . . 6 II. Physical and Chemical Characterizations . . . . . . . . . 6 (a) Particle size Analysis . . . . . . . . . . . . . . . 6 (b) Specific Surface Area Measurement . . . . . . . . . . . 9 (c) Chemical Analysis . . . . . . . . . . . . . . 10 MIXING RUBBER WITH ASPHALT . . . . . . . . . . . . . . 11 (a) Description of Mixed Materials . . . . . . . . . . . 12 (b) Measurement of Separation Value . . . . . . . . . . 12 REFERENCES •. . . . . . . . . . . . . . . . . 16 


\section{LIST OF FIGURES}

CONTENT

PAGE

Figure 1 The Relationship between Cumulative Percent . . 17 Weight and Mesh size - (30 Mesh Rubber)

Figure 2 The Relationship between Cumulative Percent . . . 18 Weight and Mesh Size - (40 Mesh Rubber)

Figure 3 The Relationship between Cumulative Percent . . . . 19 Weight and Kesh Size

Figure 4 The Relationship Between Separation Value . . . . 20 and storage Time

Figure 5 The Relationship Between Separation Value . . . . 21 and Storage Time 


\title{
A SUMMARY REPORT OF THE D. O. E. PROJECT (NO. 23242401)
}

\author{
A TEST PROGRAM FOR THE EVALUATION OF SURFACE TREATED RUBBER \\ AS AN ADDITIVE TO RUBBER MODIFIED ASPHALT
}

\section{EXECUTIVB SURARRY}

The use of ground rubber in rubber modified asphalt has gained in popularity in recent years. The advantages of using scrap tire rubber in pavement are: (1) laboratory and field study shows that ground rubber materials can enhance the performance of asphalt and improve the low and high temperature properties. Rubber modified asphalt pavement provides better performance and longer life span than conventional asphalt. (2) Using ground rubber in pavement is a way to help solve the waste tire problems and to improve our environment. A major problem in using ground rubber in asphalt has been the inability to develop a homogeneous stable mixture of rubber modified asphalt. The ground rubber will not remain in suspension in asphalt for a long enough period of time prior to application, causing many problems for end users. Typically industry is looking for a time period of days. Current technology provides only several hours at best.

The purpose of this study was to determine if surface treated rubber (provided by ETA) using chlorine gas, which creates polar groups on the surface of the rubber, can improve the shelf life of a ground rubber modified asphalt binder blend (by achieving a homogeneous mixture and allowing the rubber to remain in suspension in asphalt). Accomplishing this would extend the holding time in storage tanks or trucks without a significant loss of properties, for use in asphalt paving applications. A test program of evaluation of surface treated rubber as an additive to rubber modified asphalt under the contract of the D.O.E. project has been undertaken. This test program encompasses the physical and chemical analysis of ground rubber materials, mixing ground rubber materials (surface treated and non-surface treated ground rubber) into asphalt and the evaluation of storage stability of the rubber modified asphalt. The physical analysis of the ground rubber materials includes particle size distribution analysis and specific surface area measurement. The chemical analysis includes the acetone extract, ash, carbon black, natural rubber, moisture and rubber hydrocarbon content tests.

In mixing ground rubber into an AC-20 asphalt, four types of rubber were used. They were 40 mesh non-surface treated ground rubber, 40 mesh surface treated ground rubber by chlorine gas, 80 mesh nonsurface treated ground rubber and 80 mesh surface treated rubber by chlorine gas. The viscosity of the rubber modified asphalt was checked at various time periods of storage to assess the degree of stability of rubber particles suspended in the asphalt. 


\section{CONCLUSION}

Under the contract of the D.O.E. project, we have conducted a test program for evaluation of surface treated rubber as an additive to rubber modified asphalt. The test program has included the physical and chemical analysis or some chosen ground rubber materials including surface treated and untreated materials. The particle size analysis shows that surface treatment possibly acts like a lubrication effect to break down the agglomerates to give slightly finer particle size distribution. The data of specific surface area shows that surface treated rubber has a little larger surface area. The results of chemical analysis shows that acetone extract increased after surface treatment.

We have measured the separation values of the rubber modified asphalt and pure asphalt for different times of storage. The separation value shows that for the rubber modified asphalt, no matter whether the rubber is 40 mesh or 80 mesh, no matter whether the rubber is "surface treated or untreated, after 6 hours of storage, serious separation phenomenon were observed. Industry is typicaliy looking for storage time measured in days rather than just hours. The separation value of the asphalt mixed with the surface treated rubber is greater than that of the asphalt mixed with the untreated rubber. This means the surface treatment has not improved the storage stability of rubber in asphalt. 


\section{INTRODUCTION}

Ground rubber has been used as an additive in asphalt for road pavement for many years. Many states have on going programs to develop rubber/asphalt pavements, with several states presently using rubber in asphalt in certain applications as standard operating procedure. Laboratory and field study shows that ground rubber materials can enhance the performance of asphalt and improve the low and high temperature properties of asphalt. Rubber modified asphalt pavement provides better performance and longer life span than conventional asphalt pavement. Recent legislation Per ISTEA (Intermodal Surface Transportation Efficiency Act) Section 1038 requires states to use a certain portion of ground rubber in asphalt. In fact it is projected this would require as much as $800,000,000$ lbs of ground rubber by 1997 .

One of the problems to date has been the inability to develop a system that easily incorporates ground rubber into asphalt and allows it to remain in suspension for long enough periods of time, thus requiring the rubber to be mixed into the asphalt at the job site. This causes many problems for the end user. It is more desirable to mix the asphailt at the terminal but currently the rubber precipitates out of the mixture too soon.

This D. O. E. project was focused on the investigation of mixing surface treated rubber into asphalt and of evaluating whether the surface treated rubber by chlorine gas would remain in the suspension state in asphalt at an elevated temperature $\left(325^{\circ} \mathrm{F}\right)$ for a long enough period of time in order to solve this problem. The purpose of this project was to determine if surface treated rubber (scrap tire derived crumb) can improve the shelf life of a ground rubber modified asphalt binder blend (by achieving a more homogeneous mixture and allowing the rubber to remain in suspension in asphalt).

Under the contract of the D. O. E. project (No. 23242401), we have conducted a test program for the evaluation of surface treated rubber as an additive to rubber modified asphalt. A summary report of the project is presented hereunder. Treated material for this study was provided by Environmental Technologies Alternatives, Inc. 
PHYSICAI, AND CHEMICAL CHARACTERIZATIONS OF MATERIALS

\section{Ground Rubber Materials}

The ground rubber materials are listed as follows:

1. TR-30 original ground rubber, (TR-30).

2. TR-40 original ground rubber, (TR-40).

3. GF-80 original ground rubber, $(\mathrm{GF}-80)$.

4. Surface modified $T R-30$ ground rubber with surface treatment type \#1 by Air \& Chemical products Inc. (TR-30, T\#1).

5. Surface modified TR-30 ground rubber with surface treatment type 2 by Air \& Chemical Products Inc. (TR-30, T\$2).

6. Surface modified TR-40 ground rubber with surface treatment Type \#1 by Air \& Chemical products Inc. (TR-40, T\#1).

7. Surface modified TR-40 ground rubber with surface treatment Type \#2 by Air \& Chemical Products Inc. (TR-40, T\#2).

8. Surface modified $G F-80$ ground rubber with surface treatment Type \#1 by Air \& Chemical Products Inc. (GF-80, T\#1).

9. Surface modified GF-80 ground rubber with surface treatment Type $\$ 2$ by Air \& Chemical Products Inc. (GF-80,T $\$ 2)$.

Because an 80 mesh untreatèd rubber sample was not available from ETA, we used a similar 80 mesh material, provided by Baker Rubber, as a control sample. This had a similar particle size distribution to the treated 80 mesh rubber, and was from the same 80 mesh supplier. This means that the 80 mesh treated samples were not made from the 80 mesh control material.

\section{Physical and Chemical Characterizations}

\section{(a) Particle Size Analysis}

The particle size distribution of ground rubber materials may have impact on their processing characteristics and final properties in different applications. The surface treatment may have influence on particle size distribution. The particle size distribution of the ground rubber materials were characterized by sieve analysis. A dry weight of ground rubber material was placed on a series of sieves arranged in order of increasing fineness from the top down. The mass was then divided by these screens during the sieving process into fractions corresponding to the sieve openings. The Ro-tap sieve shaker used was Model B, C. E. Tyler - a mechanically operated sieve shaker as described in ASTM DI511[1] and described in "Testing Sieves and Their Uses" handbook[2]. The sieves used were U.S. standard sieves conforming to ASTM Specification E11[3].

The sieve analysis results are summarized in Table 1 to Table 9. Figure 1 to Figure 3 are the plots of the relationship between cumulative percent weight and mesh size according to the data in Table 1 to Table 9. 
Table 1

TR-30 Original Material

\begin{tabular}{|l|c|c|c|c|c|c|c|}
\hline Mesh Size & 30 & 40 & 60 & 80 & 100 & 120 & B. Pan \\
\hline $\begin{array}{l}\text { Material } \\
\text { Retained } \\
(8)\end{array}$ & 2.4 & 32.6 & 33.3 & 13.8 & 4.8 & 4.0 & 9.1 \\
\hline
\end{tabular}

Table 2 TR-30 Material with Treatment Type \#2

\begin{tabular}{||l|c|c|c|c|c|c|c|}
\hline Mesh Size & 30 & 40 & 60 & 80 & 100 & 120 & B. Pan \\
\hline $\begin{array}{l}\text { Material } \\
\text { Retained } \\
(\%)\end{array}$ & 1.7 & 29.9 & 33.6 & 14.8 & 4.6 & 4.3 & 11.1 \\
\hline
\end{tabular}

Table 3

TR-30 Material with Treatment Type \#2

\begin{tabular}{|l|c|c|c|c|c|c|c|}
\hline Mesh Size & 30 & 40 & 60 & 80 & 100 & 120 & B. Pan \\
\hline $\begin{array}{l}\text { Material } \\
\text { Retained } \\
(\%)\end{array}$ & 1.3 & 27.2 & 35.5 & 15.4 & 5.2 & 4.4 & 11.0 \\
\hline
\end{tabular}

Table 4

TR-40 Original Material

\begin{tabular}{||l|c|c|c|c|c|c|c|}
\hline Mesh Size & 40 & 60 & 80 & 100 & 120 & 140 & B. Pan \\
\hline $\begin{array}{l}\text { Material } \\
\text { Retained } \\
(8)\end{array}$ & 8.7 & 49.0 & 16.6 & 5.6 & 4.5 & 4.5 & 11.1 \\
\hline
\end{tabular}

Table 5 TR-40 Material with Treatment Type 1

\begin{tabular}{||c|c|c|c|c|c|c|c|}
\hline Mesh size & 40 & 60 & 80 & 100 & 120 & 140 & B. Pan \\
\hline $\begin{array}{l}\text { Material } \\
\text { Retained } \\
(8)\end{array}$ & 3.9 & 44.7 & 19.4 & 6.6 & 6.0 & 5.2 & 14.2 \\
\hline
\end{tabular}


Table 6

TR-40 Material with Treatment Type $\$ 2$

\begin{tabular}{|l|c|c|c|c|c|c|c|}
\hline Mesh Size & 40 & 60 & 80 & 100 & 120 & 140 & B. Pan \\
\hline $\begin{array}{l}\text { Material } \\
\text { Retained } \\
(\%)\end{array}$ & 3.9 & 44.8 & 20.2 & 6.9 & 5.9 & 4.8 & 13.5 \\
\hline
\end{tabular}

Table 7 80 Mesh Original Material

\begin{tabular}{|l|c|c|c|c|c|c|c|}
\hline Mesh Size & 80 & 100 & 120 & 140 & 170 & 200 & B. Pan \\
\hline $\begin{array}{l}\text { Material } \\
\text { Retained } \\
(\mathrm{q})\end{array}$ & 26.1 & 15.7 & 14.0 & 15.8 & 12.3 & 7.0 & 9.1 \\
\hline
\end{tabular}

Table 8 80 Mesh Material with Treatment Type 1

\begin{tabular}{||l|c|c|c|c|c|c|c|}
\hline Mesh Size & 80 & 100 & 120 & 140 & 170 & 200 & B. Pan \\
\hline $\begin{array}{l}\text { Material } \\
\text { Retained } \\
(\%)\end{array}$ & 21.3 & 14.1 & 16.7 & 17.9 & 13.3 & 7.8 & 8.9 \\
\hline
\end{tabular}

Table 9

80 Mesh Material with Treatment Type $\$ 2$

\begin{tabular}{||l|c|c|c|c|c|c|c|}
\hline Mesh Size & 80 & 100 & 120 & 140 & 170 & 200 & B. Pan \\
\hline $\begin{array}{l}\text { Material } \\
\text { Retained } \\
(8)\end{array}$ & 17.6 & 13.2 & 16.8 & 18.7 & 15.7 & 9.9 & 8.1 \\
\hline
\end{tabular}

From the plots of the relationship between cumulative percent weight and mesh size, we found that the treated materials act slightly finer than their control materials (untreated materials). This seems that the surface treatment acts like a lubrication to break down the particle agglomerates. 


\section{(b) Specific Surface Area Measurement}

The specific surface area of ground rubber may affect their handling and processing characteristics and the properties of end products. Surface area may also have important impact on the reactivities between ground rubber and asphalt. We have conducted the specific surface area measurement on the rubber materials used for this project. The principle of the specific surface measurement is based on the B.E.T. theory[4-6]. The Surface Area Analyzer used was Qauantasorb Surface Area Analyzer made by Quantachrome corporation.

The measured specific surface areas are listed in table 10 to table 12 .

Table 10 Specific Surface Area of 30 Mesh Ground Rubber

\begin{tabular}{|c|c|c|c|}
\hline & $\begin{array}{c}\text { TR-30 } \\
\text { (original) }\end{array}$ & $\begin{array}{c}\text { TR-30 } \\
\text { Treatment Type } \\
\$ 1\end{array}$ & $\begin{array}{c}\text { TR-30 } \\
\text { Treatment Type } \\
\text { (2 }\end{array}$ \\
\hline $\begin{array}{c}\text { Specific } \\
\text { Surface } \\
\text { Area }\left(\mathrm{m}^{2} / \mathrm{g}\right)\end{array}$ & 0.102 & 0.099 & 0.106 \\
\hline
\end{tabular}

Table 11 Specific Surface Area of 40 Mesh Ground Rubber

\begin{tabular}{|c|c|c|c|}
\hline & $\begin{array}{c}\text { TR-40 } \\
\text { (Original) }\end{array}$ & $\begin{array}{c}\text { TR-40 } \\
\text { Treatment Type } \\
\# 1\end{array}$ & $\begin{array}{c}\text { TR-40 } \\
\text { Treatment Type } \\
\$ 2\end{array}$ \\
\hline $\begin{array}{c}\text { Specific } \\
\text { Surface } \\
\text { Area }\left(\mathrm{m}^{2} / \mathrm{g}\right)\end{array}$ & 0.108 & 0.126 & 0.121 \\
\hline
\end{tabular}

Table 12 Specific Surface Area of 80 Mesh Ground Rubber

\begin{tabular}{|c|c|c|c|}
\hline & $\begin{array}{c}\text { GF-80 } \\
\text { (Original) }\end{array}$ & $\begin{array}{c}\text { GF-80 } \\
\text { Treatment Type } \\
\text { 1 }\end{array}$ & $\begin{array}{c}\text { GF-80 } \\
\text { Treatment Type } \\
\text { 2 }\end{array}$ \\
\hline $\begin{array}{c}\text { Specific } \\
\text { Surface } \\
\text { Area }\left(\mathrm{m}^{2} / \mathrm{g}\right)\end{array}$ & 0.150 & 0.183 & 0.175 \\
\hline
\end{tabular}


Comparing the specific surface areas in Table 10 to Table 11 , Wefound that the finer the material is, the larger specific surface area the materials have, which is of course expected. The treated materials show a little larger specific surface area than the untreated materials. There are little differences between the effects of two types of treated materials. For 80 mesh materials, because the treated samples were not made from the 80 mesh control material, it is hard to say whether the increase in surface area was due to the surface treatment or due to the differences in particle size distributions between the control sample and treated samples.

\section{(c) Chemical Analysis}

The chemical analysis of ground rubber materials involves the application of testing methods described in ASTM D297 - "Standard Test Methods for Rubber Products - Chemical Analysis"[7] These methods are designed to identify chemical components in a rubber compound, and are widely used in the recycled tire rubber industry. It is common to test for acetone extract, ash, carbon black, moisture, natural rubber and rubber hydrocarbon content. These parameters are expressed as the weight percentage of the tested sample. The analysis results are presented in the following:

\section{Chemical Analysis Results of TR-30 Ground Rubber} 8

TR-30(Original) TR-30 (Treatment T\#1) TR-30(Treatment T\#2)

\section{Aceto}

Ash:

Carbon Black:

Moisture:

N. R.* :

RHC** :

$$
\begin{aligned}
& 15.5 \\
& 4.4 \\
& 34.3 \\
& 0.88 \\
& 21.4 \\
& 45.8
\end{aligned}
$$
18.8
4.4
33.3
0.84
9.9
43.5

20.2

4.2

33.0

1.13

9.2

42.6 


\section{Chemical Analysis Results of TR-40 Ground Rubber}

8 TR-40(Original) TR-40 (Treatment T\#1) TR-40(Treatment T\#2)

12.1
4.1
34.0
0.84
24.8
49.8

13.9

3.9

39.9

1.22

25.2

42.3

\section{Chemical Analysis Results of 80 Mesh Ground Rubber}

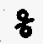

$$
\text { GF-80(Original) GF-80 (Treatment } T \$ 1) \text { GF-80(Treatment T\$2) }
$$

17.9

6.1

46.2

0.89

4.7

29.8
15.8

2.7

38.7

1.85

3.2

42.8

Note 1: *N. R. means natural rubber, ** RHC means rubber hydrocarbon

Note 2: For 80 mesh materials, the differences here between treated and untreated samples may not be due to the surface treatment, but because a different material sample was used.

\section{MIXING RUBBER WITH ASPHALT}

We chose an AC-20 asphalt, which is widely available in southern and western parts of the united states, as our study asphalt. The absolute viscosity of the $A C-20$ asphalt was 2063 Ps. We mixed rubber into asphalt at these mixing conditions: a high shear mixer (Silverson Mixer), $325^{\circ} \mathrm{F}$ to $375^{\circ} \mathrm{F}$ mixing temperature, which is easily controlled using the silverson Mixer., and 4 hours mixing time. We think that any mixing time longer than 4 hours is not practical. According to our experience high shear mixing gives better mixing results. If a high shear mixer can not provide the desired mixing results, a low shear mixer definitely will not provide the desired results. This is the reason why we chose a high shear mixer. 


\section{(a) Description of Mixed Materials}

We mixed $5 \%$ rubber into the $A C-20$ asphalt. We chose the untreated rubber as control samples. We initially picked the rubber materials with treatment type $\# 2$ as our first study material. We did this because the treatment type $\# 2$ is a higher level treatment than the treatment type \#1. If untreated sample and treated sample with treatment type \#2 can not provide a storage stable rubber modified asphalt, the rubber sample with treatment type 1 , which is in between the untreated and treated rubber sample with treatment type \#2, will also not provide a storage stable rubber modified asphalt. Any experiment using treated rubber with treatment type \#1 would have given less efficient use of time and money. If the overall experiment had been successful we would have had to test type $\$ 1$ since this would have been a lower cost approach had it too been successful. According to our experience we know that rubber material with a finer particie size distribution tends to remain in suspension for longer time periods than the rubber with coarser particle size distribution does. This is the reason why we chose $T R-40$ over $T R-30$ with treatment type \#2 as our base coarse study material. The study samples for the separation value test are listed as follows:

(1) pure AC-20 asphalt, a control sample.

(2) $5 \% \mathrm{TR}-40$ (original) $+95 \% \mathrm{AC}-20$ asphalt, serving as a control sample.

(3) $5 \%$ TR-40 surface treated rubber with treatment type $\$ 2+95 \%$ AC-20, serving as a study sample.

(4) $5 \%$ GF-80 (original) $+95 \%$ AC-20 asphalt, serving as a control sample.

(5) $5 \%$ GF-80 surface treated rubber with treatment type \$2 + 95\% AC-20 asphalt, serving as a study sample.

\section{(b) Measurement of Separation Value}

The above described samples were stored at $325^{\circ} \mathrm{F}$ for $2,4,6,8$, 12,24 and 48 hours, then the separation values for stored samples were measured. The separation value is defined as the difference between the viscosity of the material at top part and the viscosity of the material at bottom part of a storage tube. For example, the separation value is 615 PS for the AC-20 asphalt mixed with TR-40 original rubber after 2 hours storage (see Table 14). The greater the separation value, the more serious the separation of rubber from asphalt.

The test results are presented in Table 13 to Table 15. 
Table 13 Viscosity and Separation Value for Pure AC-20 Asphalt

\begin{tabular}{|c|c|c|c|c|c|c|c|}
\hline $\begin{array}{c}\text { Storage Time } \\
\text { (hours) }\end{array}$ & 2 & 4 & 6 & 8 & 12 & 24 & 48 \\
\hline $\begin{array}{c}\text { Viscosity at } \\
\text { Bottom (Ps) }\end{array}$ & 2122 & 2062 & 2075 & 2115 & 2166 & & 2102 \\
\hline $\begin{array}{c}\text { Viscosity at } \\
\text { Top (PS) }\end{array}$ & 2097 & 2085 & 2023 & 2150 & 2098 & & 2096 \\
\hline $\begin{array}{c}\text { Separation } \\
\text { Value (Ps) }\end{array}$ & 25 & $0 * \star$ & 49 & 0 & 68 & & 6 \\
\hline
\end{tabular}

** when the viscosity difference between the bottom and top is negative, separation value is considered to be zero.

* For the pure AC-20 asphalt, within experimental limits, the data in Table 13 shows no separation has occurred

Table 14 Viscosity and Separation Value for the Sample of $5 \%$ TR-40 (original) + 95\% AC-20 Asphalt

\begin{tabular}{||c|c|c|c|c|c|c|c|}
\hline $\begin{array}{c}\text { Storage Time } \\
\text { (hours) }\end{array}$ & 2 & 4 & 6 & 8 & 12 & 24 & 48 \\
\hline $\begin{array}{c}\text { Viscosity at } \\
\text { Bottom (Ps) }\end{array}$ & 5048 & 5577 & 6878 & 7648 & 7783 & 8448 & 8566 \\
\hline $\begin{array}{c}\text { Viscosity at } \\
\text { Top (PS) }\end{array}$ & 4543 & 4033 & 3756 & 3984 & 3793 & 3782 & 3884 \\
\hline $\begin{array}{c}\text { Separation } \\
\text { Value (Ps) }\end{array}$ & 615 & 1544 & 3122 & 3664 & 3990 & 4666 & 4682 \\
\hline
\end{tabular}

Note: A larger separation value indicates that more rubber has fallen to the bottom of the test tube, thus increasing the viscosity. During the experiment actual rubber particles could be seen at the bottom as separation progressed. 
Table 15 Viscosity and Separation Value for the Sample of 58 TR-40 (Treatment Type $\$ 2$ ) +958 AC-20 Asphalt

\begin{tabular}{||c|c|c|c|c|c|c|c|}
\hline $\begin{array}{c}\text { storage Time } \\
\text { (hours) }\end{array}$ & 2 & 4 & 6 & 8 & 12 & 24 & 48 \\
\hline $\begin{array}{c}\text { Viscosity at } \\
\text { Bottom (PS) }\end{array}$ & 6445 & 7729 & 8724 & 9013 & 10728 & 12961 & 14376 \\
\hline $\begin{array}{c}\text { viscosity at } \\
\text { Top (PS) }\end{array}$ & 5885 & 5034 & 5061 & 4989 & 5026 & 5062 & 5519 \\
\hline $\begin{array}{c}\text { Separation } \\
\text { Value (Ps) }\end{array}$ & 560 & 2705 & 3663 & 4024 & 5702 & 7899 & 8857 \\
\hline
\end{tabular}

Table 16 Viscosity and Separation Value for the Sample of 58 GF-80 (original) + 95\% AC-20 Asphait

\begin{tabular}{|c|c|c|c|c|c|c|c|}
\hline $\begin{array}{c}\text { Storage Time } \\
\text { (hours) }\end{array}$ & 2 & 4 & 6 & 8 & 12 & 24 & 48 \\
\hline $\begin{array}{c}\text { Viscosity at } \\
\text { Bottom (PS) }\end{array}$ & 5251 & 5530 & 6348 & 7143 & 9171 & 9408 & 9820 \\
\hline $\begin{array}{c}\text { Viscosity at } \\
\text { Top (Ps) }\end{array}$ & 5243 & 4729 & 4561 & 4235 & 4056 & 4119 & 3954 \\
\hline $\begin{array}{c}\text { Separation } \\
\text { Value (PS) }\end{array}$ & 8 & 801 & 1787 & 2908 & 5106 & 5289 & 5866 \\
\hline
\end{tabular}

Table 17 Viscosity and Separation Value for the sample of $5 \%$ GF-80 (Treatment Type \#2) + 958 AC-20 Asphalt

\begin{tabular}{||c|c|c|c|c|c|c|c|}
\hline $\begin{array}{c}\text { Storage Time } \\
\text { (hours) }\end{array}$ & 2 & 4 & 6 & 8 & 12 & 24 & 48 \\
\hline $\begin{array}{c}\text { Viscosity at } \\
\text { Bottom (Ps) }\end{array}$ & 7033 & 7627 & 7697 & 8816 & 10252 & 12258 & 13852 \\
\hline $\begin{array}{c}\text { Viscosity at } \\
\text { Top (Ps) }\end{array}$ & 6502 & 5815 & 5284 & 5196 & 5238 & 5205 & 5269 \\
\hline $\begin{array}{c}\text { Separation } \\
\text { Value (Ps) }\end{array}$ & 531 & 1812 & 2413 & 3620 & 5014 & 7053 & 8583 \\
\hline
\end{tabular}


From the data in Table 14 to Table 17, we found that the increasing separation values indicate the separation was occurring and the amount is time dependent. comparing the viscosity of treated and untreated samples, we found that the surface treated material increased both the viscosities at top and bottom parts of the storage tube.

Table 18 Summary of Separation Values (Ps)

\begin{tabular}{|c|c|c|c|c|c|c|c|}
\hline $\begin{array}{c}\text { Storage Time } \\
\text { (hours) }\end{array}$ & 2 & 4 & 6 & 8 & 12 & 24 & 48 \\
\hline Pure AC-20 & $\star$ & $*$ & $\star$ & $\star$ & $\star$ & $\star$ & $\star$ \\
\hline $\begin{array}{c}\text { AC-20+5\% } \\
\text { TR-40 }\end{array}$ & 615 & 1544 & 3122 & 3664 & 3990 & 4666 & 4682 \\
\hline $\begin{array}{c}\text { AC-20+5\% } \\
\text { TR-40,T \#2 }\end{array}$ & 560 & 2705 & 3663 & 4024 & 5702 & 7899 & 8857 \\
\hline $\begin{array}{c}\text { AC-20+5\% } \\
\text { GF-80 }\end{array}$ & 8 & 801 & 1787 & 2908 & 5106 & 5289 & 5866 \\
\hline $\begin{array}{c}\text { AC-20+5\% } \\
\text { GF-80, T } \$ 2\end{array}$ & 531 & 1812 & 2413 & 3620 & 5014 & 7053 & 8583 \\
\hline
\end{tabular}

Where * means no separation occurred for the pure AC-20 asphalt.

Figure 4 and Figure 5 are the relationship between separation value and storage time for 40 mesh rubber modified asphalt and 80 mesh rubber modified asphalt respectively.

The results above shows that for the rubber modified asphalt, no matter whether the rubber is 40 mesh or 80 mesh, no matter whether the rubber is surface treated or untreated, after 6 hours of storage, serious separation phenomenon were observed. The separation value of the asphalt mixed with the surface treated rubber is greater than that of the asphalt mixed with the untreated rubber. This means the surface treated material mixed with asphalt compared to the non-surface treated material has not improved the storage stability or has actually caused it to be reduced. 


\section{REFBRBNCES:}

1. ASTM D1511, "Standard Test Methods for Carbon Black - Pellet Size Distribution." Annual Book of ASTM Standards, Vol. 09.01, 1991.

2. C.E. Tyler Industrial Products, Combustion Engineering Inc., "Testing Sieves and Their Uses." Handbook 53, 1976 Edition.

3. ASTM Ell, "Standard Specification for wire-cloth sieves for Testing Purposes." Annual Book of ASTM Standards, Vol. 14.02, 1991.

4. T. Allen, "Particle size Measurement", 2nd ed. John Wiley \& Sons, New York, 1975.

5. S. Lowell, Joan E. Shield, "Powder Surface Area and Porosity", 2nd ed. Chapman and Hall, London, 1984.

6. Quantachrome Corporation, Quantasorb Surface Area Analyzer Manual. p. XI-3

7. ASTM Standard D297, "Standard Test Methods for Rubber Products - Chemical Analysis." Annual Book of ASTM Standards, Vol. 09.01, 1991. 


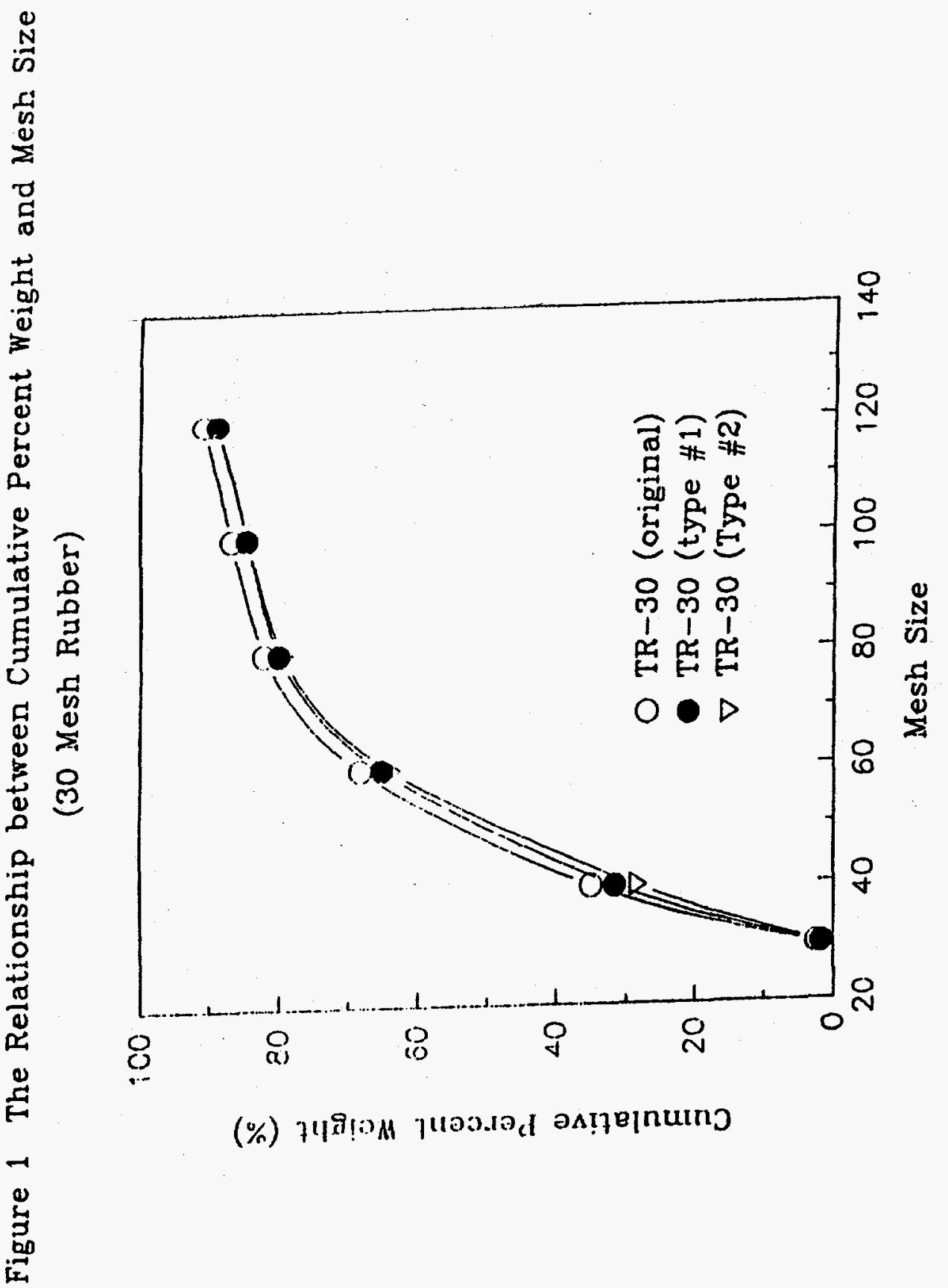




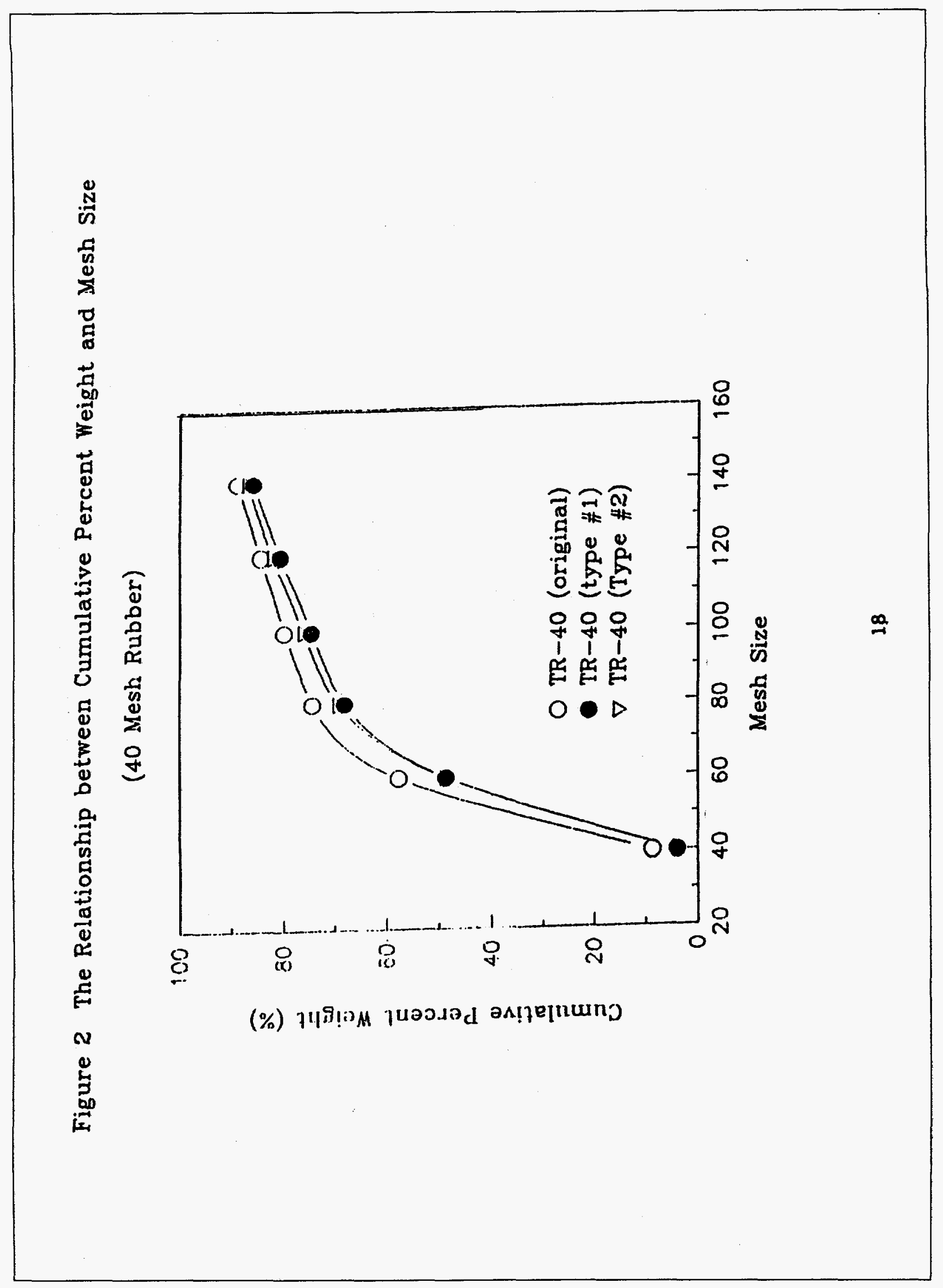




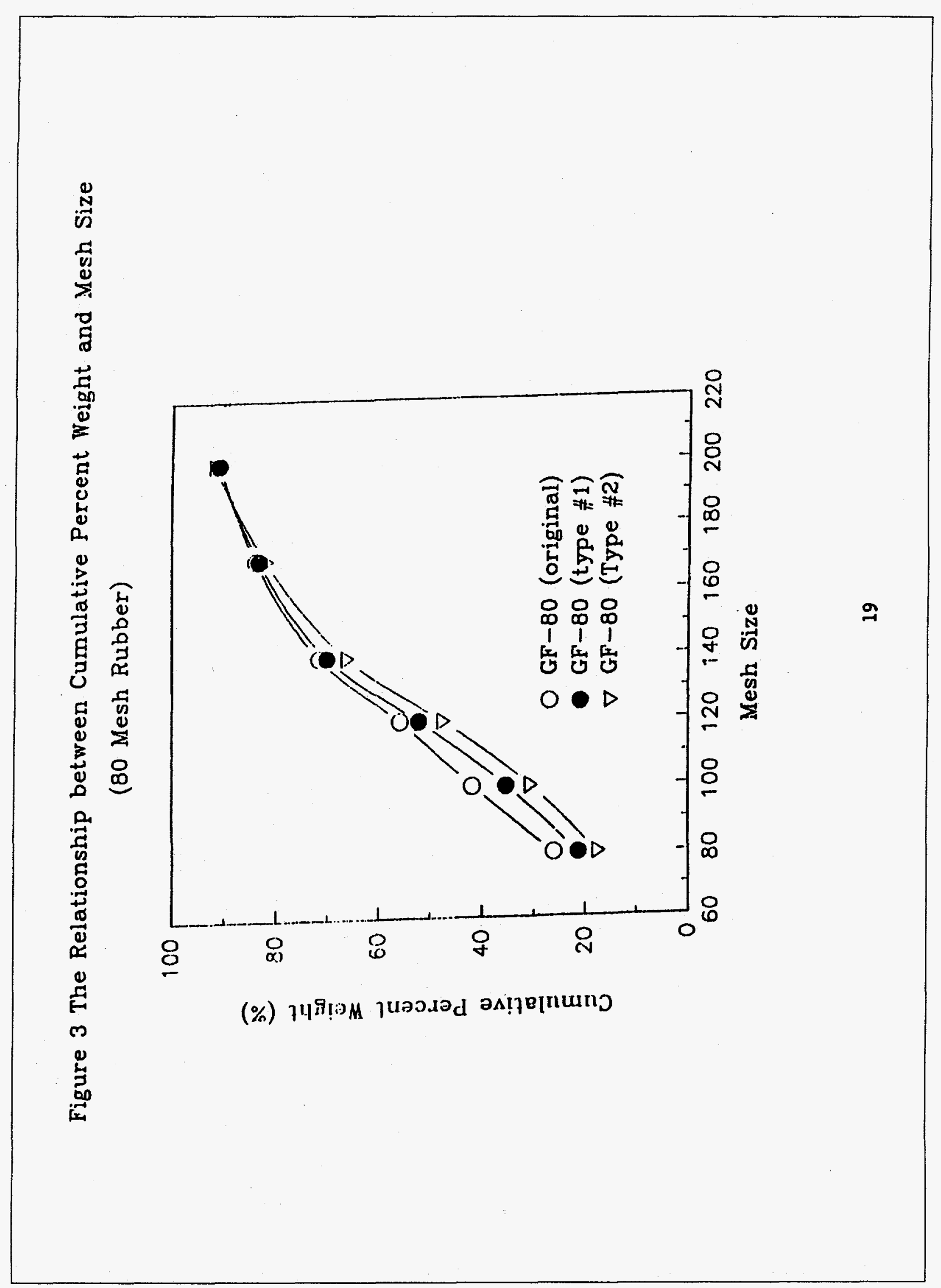




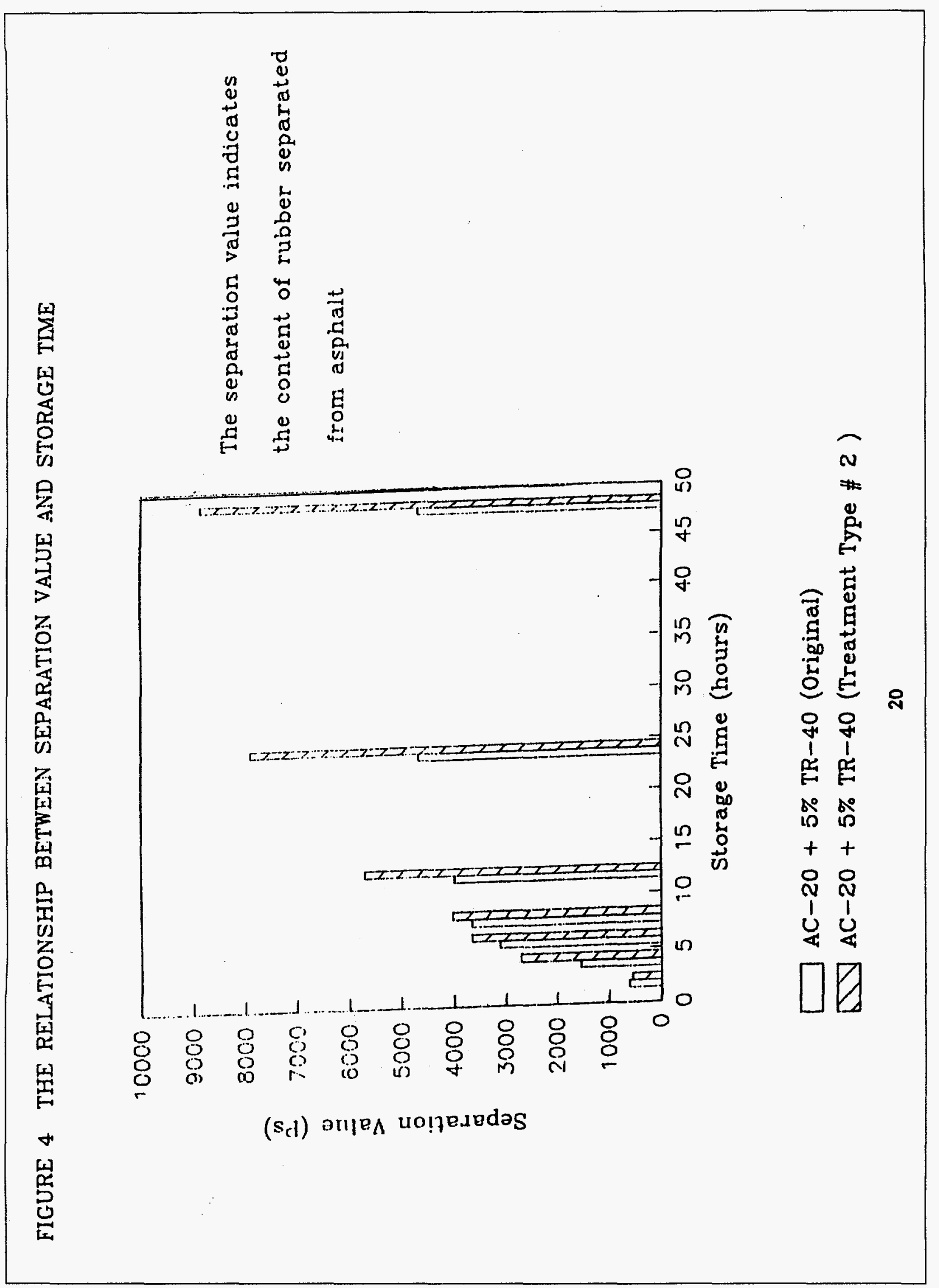




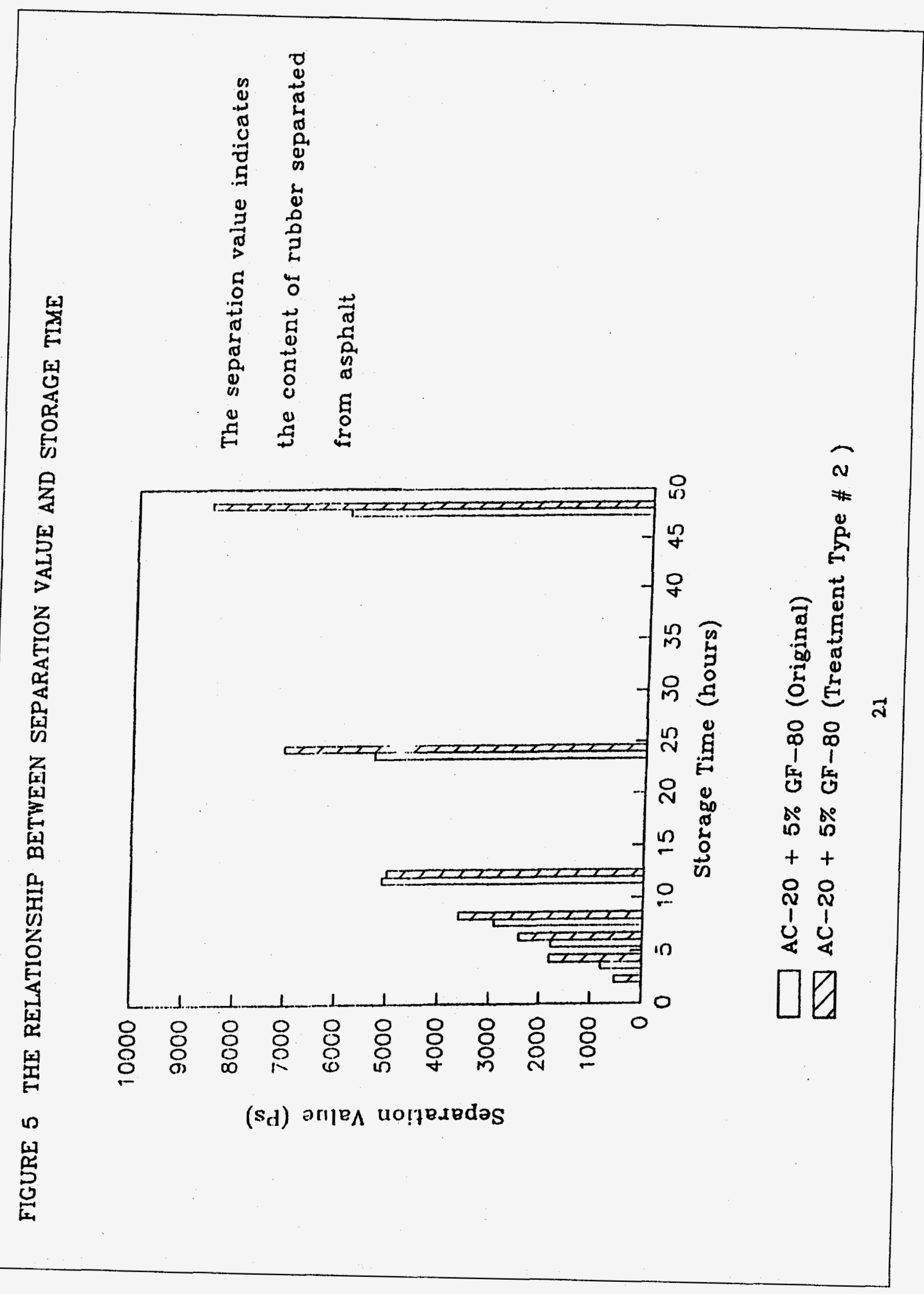


